\title{
Aggregate Returns to Scale and Embodied Technical Change: Theory and Measurement Using Stock Market Data
}

\author{
John Laitner (University of Michigan) \\ Dmitriy Stolyarov*(University of Michigan)
}

July 29, 2003

\begin{abstract}
We develop a new general equilibrium growth accounting framework that features increasing returns to scale, imperfect competition and incorporates technological revolutions into the description of technical progress. We propose a way to tell apart revolutionary changes in technology and incremental innovations using stock market data. We use our framework to jointly estimate the overall embodied TFP change during 1953-1995 and the aggregate output elasticity. We find that the IT revolution raised the aggregate TFP level by about $20 \%$. We suggest a 1.09-1.11 range for the aggregate returns to scale.
\end{abstract}

Key words: embodied technological change, technological revolutions, aggregate returns to scale, productivity analysis.

JEL classification: E44, O3, O41, O47

\section{Introduction}

Economic history provides a number of examples of progress resulting from inventions that transform production (Landes, 1969, Rosenberg, 1982, Mokyr, 1990). Many commentators characterize the recent information technology revolution as such a transforming change. This paper develops a new general equilibrium growth accounting framework with embodied technical progress that can incorporate technological revolutions as well as continuous change and also features increasing returns to scale and imperfect competition. Using data on stock market values, financial rates of return, input and output quantities, and investment good prices, we attempt to estimate the degree of aggregate returns to scale in the U.S. economy and the relative importance of incremental progress and technological revolutions in the last 50 years.

Following Solow (1960) and more recent work of Hulten (1992), Greenwood et al. (1997), Greenwood and Jovanovic (2001), and others, this paper assumes that new capital goods embody technological change. Although invention comes for free, the economy must invest in new physical capital

\footnotetext{
*Corresponding Author: Professor Dmitriy Stolyarov, Department of Economics, University of Michigan, 611 Tappan Ave, Room 238, Ann Arbor, MI 48109-1220, USA; Telephone: 734-647-5609; Fax 734-764-2769; E-mail: stolyar@umich.edu. The authors thank seminar participants at the 2003 Carnegie-Rochester Conference, 2002 meetings of the Society for Economic Dynamics, the University of Michigan, and our discussant, Peter Rousseau.
} 
and applied knowledge in order for a new technology to enhance production. Given the process for the basic technology, our general equilibrium framework determines time paths of prices and quantities.

Despite the complexity of our model, the aggregate properties and, surprisingly, the simple equation of motion of Solow (1960) carry over. This makes it straightforward to use our model as a general equilibrium growth accounting framework. The model has three elements distinct from Solow's (1960) analysis: (1) we incorporate drastic technological innovations into the description of technological change; (2) we generalize the notion of capital to include intangible stocks of applied knowledge as well as physical plant and equipment; and, (3) we allow the possibility of increasing returns to scale. The first new element makes our framework potentially consistent with the popular idea that the U.S. economy underwent a profound change due to the IT revolution, and it relates transforming changes to low frequency stock market cycles. The second element allows our model to match recent large discrepancies between the market value of businesses and the production cost of their physical capital (see, for example, Hall, 2001 and Laitner and Stolyarov, 2002). The third element enables us to derive new estimates of aggregate returns to scale and to identify separately the contribution of input accumulation to growth.

Our work links to three different literatures on productivity analysis, technological change, and growth. First, this paper is related to the productivity analysis literature based on general equilibrium models of embodiment, such as Greenwood et al. (1997), Gort et al. (1999), and Greenwood and Jovanovic (2001). From a theoretical perspective, our model differs from existing models of embodiment in the three ways mentioned above. Also, we use a calibration procedure that matches the time paths of macroeconomic variables rather than just the variables' long-run average values. Lastly, we bring stock market and financial rate of return data into the analysis.

Second, our model relates to the literature on general purpose technologies (GPT), particularly Helpman and Trajtenberg (1998) and Howitt (1998). The GPT literature explicitly models the invention process that generates endogenous growth. We instead take the process for basic technology to be exogenous, and focus on setting up the production sector in a way that is suitable for bringing our model to data.

Third, our work relates to the empirical productivity analysis literature, particularly to the work following Hall (1990), which re-estimates the Solow residual without imposing constant returns to scale and perfect competition. Hall (1990) finds a surprisingly high degree of increasing returns to scale, and he raises the issue of how difficult it is to identify separately returns to scale and TFP growth. Much of the subsequent literature (e.g., Caballero and Lyons, 1992, Basu and Fernald 1995, 1997, to name just a few examples) focuses on overcoming the problem and providing unbiased estimates of aggregate returns to scale. To this day, there is no broad agreement in this literature on the degree of aggregate returns to scale. Our first contribution to this literature is to provide a new approach that relies on general equilibrium, rather than firm-level, theory. Our second contribution is that we measure technological progress both from the relationship of input and output quantities and through changes in stock market valuations and the price of investment goods per "efficiency unit."

Our theoretical steps yield a system of dynamic equations for the economy's aggregate variables. We use the system to estimate the model's parameters with post-WWII U.S. data. We find the data is consistent with a dramatic TFP increase from a technological revolution occurring around 1972-1974, and it is inconsistent with smooth TFP growth alone over the entire period. We estimate that the IT revolution has raised the aggregate TFP level by 15 to 20 percent, and that it accounts for about 40 percent of overall productivity growth during 1953-1995. Our analysis warns that measuring neutral technological change as the difference between productivity advance and the rate 
of embodied technological change may overstate its contribution to growth: if technological change is punctuated, the capital stock will grow faster than output after revolutions, so capital deepening can masquerade as neutral technological change. For the same reason, productivity decompositions based on balanced growth approximations may be inaccurate, especially when the sample period is not much longer than the interval between technological revolutions.

We use our model to estimate the aggregate degree of increasing returns to scale and to disentangle growth due to productivity improvement from growth due to input accumulation. Our preferred point estimates of the aggregate output elasticity range from 1.09 to 1.11 and have $95 \%$ confidence intervals which lie above 1 and below 1.20 .

The paper proceeds as follows. Section 2.1 introduces the model and characterizes the steady state equilibrium given the level of basic technology. Section 2.2 allows the basic technology to progress stochastically in discrete upward steps. For each technology level, the model has a unique steady-state equilibrium, and the economy converges toward the steady state between changes in technology. Section 2.3 considers continuous, or combined continuous and discrete, technological progress. Section 3 establishes the correspondence between the model's variables and quantities in the data, describes our estimation strategy and presents our parameter estimates. Section 4 discusses estimation results, and Section 5 concludes.

\section{A Model with Increasing Returns}

In this section we propose a simple model that incorporates a generalized notion of capital combining tangible and intangible elements. There are firm-level increasing returns to scale and imperfect competition.

\subsection{Stationary Technology}

Aggregate Economy. The production sector is a continuum of symmetric industries indexed by $j \in[0,1]$ (e.g., Dixit and Stiglitz (1977)). Each firm is small in relation to the entire economy, but not relative to its own industry. Individual firms may have constant or increasing returns to scale in labor and capital. If returns to scale are increasing - the case which is this paper's focus - at each date $t$, within each industry $j, N_{j t}$ firms operate in a Cournot oligopoly, producing the same output good. Nevertheless, entry is free, so equilibrium profits are zero.

Let the date $t$ output of industry $j$ be $Y_{j t}$. When households consume or firms invest in physical capital and knowledge, they care only about obtaining units of the aggregative commodity

$$
Y_{t}=\left[\int_{0}^{1}\left[Y_{j t}\right]^{\eta} d j\right]^{1 / \eta}, \quad \eta<1, \quad \eta \neq 0 .
$$

Letting $P_{j t}$ be the price of the output of industry $j$, two-step decision making requires a price index

$$
\left[\int_{0}^{1}\left[P_{j t}\right]^{1-\epsilon} d j\right]^{\frac{1}{1-\epsilon}}, \quad \epsilon \equiv \frac{1}{1-\eta}
$$

for the aggregate commodity. We normalize this price index to 1 ; aggregate (1) is our numeraire. With such a normalization, $Y_{t}$ also equals total expenditure on the aggregate commodity.

Aggregate output is homogeneously divisible into consumption, $C_{t}$, and investment. Investment builds the stock of the capital composite $M$. The latter includes both physical and intangible capital. We have 


$$
Y_{t}=C_{t}+\dot{M}_{t}+\delta \cdot M_{t}
$$

where $\delta$ is the rate of depreciation. Assume that the economy saves a constant fraction $\sigma$ of its income. Then

$$
\dot{M}_{t}+\delta \cdot M_{t}=\sigma \cdot Y_{t}, \quad \sigma \in(0,1) .
$$

Assume that investment is irreversible:

$$
\dot{M}_{t}+\delta \cdot M_{t} \geq 0 \text {. }
$$

Irreversibility will be important when we discuss technological change: because TFP, which $Z$ measures, is embodied, if it rises abruptly, firms would like to disinvest, exchanging their old capital and know-how for new. However, (2) rules that out.

Finally, let the aggregate labor force grow exponentially:

$$
L_{t}=L_{0} \cdot e^{n \cdot t}
$$

Firms. Firms produce output with capital $(m)$ and labor $(l)$. The output of firm $f$ in industry $j$ at time $t$ is

$$
y_{f j t}=Z \cdot\left[m_{f j t}\right]^{\alpha}\left[l_{f j t}\right]^{\nu}, \alpha+\nu \equiv \gamma \geq 1, \alpha<1,
$$

where $m_{f j t}$ is the firm's current stock of tangible and intangible capital, $l_{f j t}$ is its labor input, and $Z$ is the level of the economy's basic technology. Firms have non-decreasing returns to scale in $m$ and $l$. We assume that the firms purchase $m$ and $l$, but that $Z$ is freely available to all. The production function can have either increasing (if $\gamma>1$ ) or constant (if $\gamma=1$ ) returns to scale.

Let $W_{t}$ be the wage for labor and $R_{t}$ be the rental fee on capital. Each industry's output is homogeneous. Given the output of all other firms in the industry, firm $f$ chooses $m_{f j t}$ and $l_{f j t}$ to maximize its current profit. Since there is free entry, the number of firms $N_{j t}$ in each industry $j$ adjusts until every firm's profit is zero.

For simplicity, we do not require an integer numbers of firms. The sum over a non-integer number of firms should be taken to mean

$$
\sum_{f=1}^{N} x_{f}=x_{1}+\ldots+x_{[N]}+\{N\} \cdot x_{[N]+1},
$$

where $[N]$ denotes the integer part and $\{N\}$ denotes the fractal part.

We can now define an equilibrium with stationary $Z$.

Definition: An equilibrium is a sequence of functions of time that denote factor and output prices

$$
\left\{W_{t}, R_{t}, P_{j t}\right\}, t \geq 0
$$

quantities

$$
\left\{Y_{t}, Y_{j t}, y_{f j t}, M_{t}, m_{f j t}, l_{f j t}\right\}, t \geq 0, \quad f=1, \ldots, N_{j t}, j \in[0,1],
$$

firm profits

$$
\pi_{f j t} \equiv P_{j t} \cdot y_{f j t}-R_{t} \cdot m_{f j t}-W_{t} \cdot l_{f j t}, t \geq 0, \quad f=1, \ldots, N_{j t}, j \in[0,1]
$$


and the number of firms by industry

$$
N_{j t}>1, t \geq 0, j \in[0,1],
$$

satisfying the following relations

$$
\begin{gathered}
y_{f j t}=Z\left[m_{f j t}\right]^{\alpha}\left[l_{f j t}\right]^{\nu} \\
M_{t}=\int_{0}^{1} \sum_{f=1}^{N_{j t}} m_{f j t} d j \\
Y_{t}=\left(\int_{0}^{1}\left[Y_{j t}\right]^{\eta} d j\right)^{\frac{1}{\eta}}=\left(\int_{0}^{1}\left[\sum_{f=1}^{N_{j t}} y_{f j t}\right]^{\eta} d j\right)^{\frac{1}{\eta}} ; \\
{\left[\int_{0}^{1}\left[P_{j t}\right]^{1-\epsilon} d j\right]^{\frac{1}{1-\epsilon}}=1, \quad \epsilon \equiv \frac{1}{1-\eta} ;} \\
Y_{j t}=Y_{t} \cdot\left[P_{j t}\right]^{-\epsilon} ;
\end{gathered}
$$

and the equilibrium conditions

1. Firms choose $\left(m_{f j t}, l_{f j t}\right)$ to maximize profits

$$
\left(m_{f j t}, l_{f j t}\right) \in \arg \max \pi_{f j t} ; \text { all } f, j, t ;
$$

2. Firms earn zero economic profit

$$
\pi_{f j t}=0 ; \text { all } f, j, t
$$

3. Labor and goods markets clear

$$
\begin{gathered}
L_{t}=\int_{0}^{1} \sum_{f=1}^{N_{j t}} l_{f j t} d j \\
\dot{M}_{t}+\delta M_{t}=\sigma Y_{t}
\end{gathered}
$$

4. The initial condition $M_{0}$ is given.

Many components of the definition have been discussed above. We require $N_{j t}>1$ because we focus on oligopoly rather than monopoly. Equations (S2)-(S3) define aggregative variables, (S4) is our price normalization, (S5) describes the demand curve in each industry, (S7) is a consequence of free entry, and (S9) is a consequence of our simple saving function. Also note that with free entry, any complex strategy of a firm that conditions its current output on the history of outputs of its rivals can do no better than zero profit in every period. Firms have nothing to gain from collusion; therefore, we restrict a firm's output choice to depend only on the current output of its rivals.

The following lemma shows that in equilibrium, first-order conditions are necessary and sufficient for profit maximization on the part of firms.

Lemma 1: Suppose a candidate equilibrium satisfies all conditions for equilibrium except possibly profit maximization (S6). Let $l_{f j t}>0$ and $m_{f j t}>0$ satisfy the first order conditions

$$
W_{t}=\nu \cdot m r_{f j t} \cdot \frac{y_{f j t}}{l_{f j t}}
$$




$$
R_{t}=\alpha \cdot m r_{f j t} \cdot \frac{y_{f j t}}{m_{f j t}}
$$

where marginal revenue is

$$
m r_{f j t}=P_{j t}\left(1-(1-\eta) \frac{y_{f j t}}{Y_{j t}}\right) .
$$

Then condition (S6) holds. Conversely, (4)-(5) must hold in any equilibrium .

Proof: See Appendix.

Since there are no pure profits in the economy, $M_{t}$ is, by construction, the market value of private-sector net worth. It turns out that there is a unique equilibrium in which the aggregate economy behaves like a standard Solow (1956) model with $M_{t}$ as a state variable. Proposition 1 derives the aggregate equation of motion and proves the existence and uniqueness of equilibrium.

Proposition 1: Existence of Equilibrium with Stationary Technology. There exists a unique equilibrium for any initial condition $M_{0}>0$. In this equilibrium, all industries behave symmetrically and all firms produce the same output.

$$
\begin{gathered}
N_{j t}=N_{t}=\frac{\gamma}{\gamma-1}(1-\eta), \\
P_{j t}=P_{t}=1, \\
Y_{j t}=Y_{t}=\frac{Z}{N^{\gamma-1}}\left[M_{t}\right]^{\alpha}\left[L_{t}\right]^{\nu} \text { all } j, \\
y_{f j t}=y_{t}=\frac{Y_{t}}{N}, \quad m_{f j t}=m_{t}=\frac{M_{t}}{N}, \quad l_{f j t}=l_{t}=\frac{L_{t}}{N} .
\end{gathered}
$$

The aggregate equation of motion is

$$
\dot{M}_{t}=\sigma \bar{Z}\left[M_{t}\right]^{\alpha}\left[L_{t}\right]^{\nu}-\delta M_{t} \text { all } t
$$

where

$$
\bar{Z} \equiv \frac{Z}{N^{\gamma-1}}
$$

Proof: See Appendix.

If TFP level $Z$ never changes, (7) shows the economy will converge to the steady state equilibrium (SSE) in which all variables grow at constant rates and $R_{t}$ is constant. Formally, letting $g_{x} \equiv \dot{x}_{t} / x_{t}$ for any variable $x$, we have the following corollary to Proposition 1

Corollary: For any SSE, we must have

$$
\begin{gathered}
g_{N}=g_{R}=0, \quad g_{W}=\frac{\gamma-1}{1-\alpha} n, \\
g_{Y}=g_{y}=g_{M}=\frac{\nu \cdot n}{1-\alpha} .
\end{gathered}
$$

Proof: See Appendix.

Proposition 1 shows that the analytical simplicity of the basic Solow (1956) model carries over to the case with increasing returns to scale and oligopoly. The next sections characterize the equilibrium time path of the economy with abrupt, embodied technological change. 


\subsection{Technological revolutions}

To capture the idea that technological revolutions occur exogenously and randomly, assume that $Z$ evolves over time through a series of discrete upward steps. Let an exogenous Poisson process determine the timing of the steps: if the initial time is $t=0$, let $\left\{t_{i}\right\}_{i=1}^{\infty}$ with

$$
0<t_{1}<t_{2}<\ldots
$$

be the dates of technological revolutions, with Poisson realizations determining $t_{i}-t_{i-1}$. If the corresponding sequence of TFP levels is

$$
Z_{0}<Z_{1}<Z_{2}<\ldots
$$

assume the size of each step $Z_{i} / Z_{i-1}$ is an independent draw from an exogenous distribution. Let $\iota(t)$ be the index of the frontier technology at time $t$ :

$$
\iota(t) \equiv i, \quad t \in\left[t_{i}, t_{t+1}\right), \quad i \geq 0 .
$$

Under these assumptions, the length of the interval since the last transformation provides no information about the timing of the next revolution, and the level of $Z_{i}$ provides no insight about the relative magnitude of $Z_{i+1} / Z_{i}$.

Consider first the model's reaction to a single change in $Z$. For $0 \leq t<t_{1}$, suppose the level of the basic technology is $Z=Z_{0}$; for $t \geq t_{1}$, let $Z=Z_{1}>Z_{0}$. After date $t_{1}$, businesses can invest in capital stocks that embody the unambiguously more productive technology $Z_{1}$. It would take only $\left[Z_{0} / Z_{1}\right]^{1 / \alpha}<1$ units (measured in consumption goods) of $M_{1}$ to produce as much output as one unit of $M_{0}$, when they are combined with the same quantity of labor. Consequently, in our equilibrium below, the resale price (relative to consumption good) of old capital $M_{0}$ drops at time $t_{1}$ from 1 to $P_{0}^{M}=\left[Z_{0} / Z_{1}\right]^{1 / \alpha}$. Although new investments embodying the old technology remain feasible after the revolution, they entail an immediate capital loss from 1 to $P_{0}^{M}$. Agents choose to invest, therefore, only in the frontier technology $Z_{1}$. This causes irreversibility constraint (2) to bind for old vintage capital.

As in Solow (1960), it is also the case that aggregate production function (6) from $t<t_{1}$ remains valid after $t_{1}$ provided we substitute $Z=Z_{1}$ for $Z=Z_{0}$ and define aggregate capital $M_{t}=P_{0}^{M} \cdot M_{0 t}+M_{1 t}$. Proposition 2 establishes this formally.

To extend our reasoning to an endless series of changes in $Z$, we need a new definition of equilibrium. Let $P_{i t}^{M}$ be the time $-t$ resale price of a unit of capital embodying technology $Z_{i}$; let

$m_{f j t}^{i}$ be the capital embodying $Z_{i}$ which firm $f$ in industry $j$ utilizes at $t$; and, let $l_{f j t}^{i}$ be the labor which firm $f$ uses with machinery embodying technology $Z_{i}$. The firm takes input prices and the industry demand curve as given, and it chooses how much output to produce, given the output of its rivals, and which technologies to use (assume free disposal). Rental companies own the capital and rent it to producers at a fee $R_{i t}$ per dollar of capital of vintage $i$. The rental business is subject to free entry.

Definition: An equilibrium is a sequence of functions of time that denote prices

$$
\left\{W_{t}, R_{i t}, P_{i t}^{M}, P_{j t}\right\}, \quad i=0, \ldots, \iota(t), \quad t \geq 0
$$

quantities

$$
\left\{Y_{t}, Y_{j t}, M_{i t}, I_{i t}, y_{f j t}, m_{f j t}^{i}, l_{f j t}^{i}\right\}, \quad t \geq 0, \quad f=1, \ldots, N_{j t}, \quad i=0, \ldots, \iota(t), \quad j \in[0,1],
$$


firm profits

$$
\pi_{f j t} \equiv P_{j t} \cdot y_{f j t}-\sum_{i=0}^{\iota(t)}\left[R_{i t} \cdot P_{i t}^{M} \cdot m_{f j t}^{i}+W_{t} \cdot l_{f j t}^{i}\right], \quad t \geq 0, \quad f=1, \ldots, N_{j t}, \quad j \in[0,1],
$$

and number of firms by industry

$$
N_{j t}>1, \quad t \geq 0, \quad j \in[0,1],
$$

that satisfy the following relations

$$
\begin{gathered}
y_{f j t}=\sum_{i=0}^{\iota(t)} Z_{i} \cdot\left[m_{f j t}^{i}\right]^{\alpha} \cdot\left[l_{f j t}^{i}\right]^{\nu} ; \\
M_{i t}=\int_{0}^{1} \sum_{f=1}^{N_{j t}} m_{f j t}^{i} d j, \quad i=0, \ldots, \iota(t) ; \\
Y_{t}=\left(\int_{0}^{1}\left[Y_{j t}\right]^{\eta} d j\right)^{\frac{1}{\eta}}=\left(\int_{0}^{1}\left[\sum_{f=1}^{N_{j t}} y_{f j t}\right]^{\eta} d j\right)^{\frac{1}{\eta}} ; \\
P_{\iota(t), t}^{M}=1 ; \\
{\left[\int_{0}^{1}\left[P_{j t}\right]^{1-\epsilon} d j\right]^{\frac{1}{1-\epsilon}}=1, \quad \epsilon \equiv \frac{1}{1-\eta} ;} \\
Y_{j t}=Y_{t} \cdot\left[P_{j t}\right]^{-\epsilon} ;
\end{gathered}
$$

and the equilibrium conditions

1. Firms choose $\left(m_{f j t}^{i}, l_{f j t}^{i}\right)_{i=0}^{\iota(t)}$ to maximize profits

$$
\left(m_{f j t}^{i}, l_{f j t}^{i}\right) \in \arg \max _{\left\{m_{f j t}^{x}, l_{f j t}^{x}\right\}, x=0, \ldots, \iota(t)}\left\{\pi_{f j t}\right\}, \text { all } i=0, \ldots, \iota(t), f, j, t ;
$$

2. Firms earn zero economic profit

$$
\pi_{f j t}=0, \text { all } f, j, t
$$

3. Labor and goods markets clear

$$
\begin{gathered}
L_{t}=\int_{0}^{1} \sum_{f=1}^{N_{j t}} \sum_{i=0}^{\iota(t)} l_{f j t}^{i} d j, \\
\sum_{i=0}^{\iota(t)} P_{i t}^{M} I_{i t}=\sigma Y_{t}
\end{gathered}
$$

4. Capital stocks follow their laws of motion

$$
\dot{M}_{i t}=I_{i t}-\delta M_{i t}, i=0, \ldots, \iota(t), t \geq t_{i} ;
$$


given the initial conditions $M_{0,0}$ and

$$
M_{i, t_{i}}=0, i=1, \ldots, \iota(t)
$$

5. Investment is irreversible and it seeks the highest return:

$$
I_{i t} \geq 0 \text { for all } i \geq 0, t, I_{i t}>0 \Longleftrightarrow i \in \arg \max _{x=\{0, . ., L(t)\}}\left\{P_{x t}^{M}\right\} .
$$

If $\gamma>1$, the convexity of the production function implies that each firm will use just one vintage of capital. Furthermore, the resale price of older vintages must reflect their lower efficiency. Finally, the price of different vintages will adjust in such a way that all firms will end up hiring the same amount of labor and supplying the same quantity of output. Formally, we have

Lemma 2: In any equilibrium,

(i)

$$
P_{i t}^{M}=\left[\frac{Z_{i}}{Z_{\iota(t)}}\right]^{1 / \alpha} \text { all } i=0, \ldots, \iota(t), t \geq t_{i}
$$

(ii)

$$
R_{i t}=R_{t} \text { all } i=0, \ldots, \iota(t), t \geq t_{i}
$$

(iii) All new investment goes to the capital that embodies the latest technology ८ $(t)$,

(iv) Each firm uses a single vintage of capital,

(v) Any firm employs the same amount of labor and produces the same quantity of output.

Proof: See Appendix.

In equilibrium, the price of an old vintage of capital falls over time in a series of discrete downward steps that coincide with changes in technology. All new investment is used to purchase capital that embodies the current frontier technology $\iota(t)$. Capital is allocated across firms in such a way that the firms are indifferent over which vintage to use. All firms employ the same amount of labor, the same number of efficiency units of capital, and, thus, produce equal output. The number of firms in an industry stays constant over time even though firms continue switching technologies.

In any equilibrium, all industries must behave in a symmetric fashion: profit maximization and zero profit conditions cannot hold unless all firms produce equal output. Because of this symmetry, any distribution of technology use by industry is consistent with equilibrium. However, the aggregate fraction of firms that use a particular technology is uniquely determined. Let $\varphi\left(Z_{i}, t\right)$ denote the fraction of firms in the economy that use technology $Z_{i}$. As the composition of capital stock changes over time due to new investment and depreciation, capital has to be constantly reallocated across firms to maintain equilibrium. This is why the fraction of firms using a particular technology will change over time. The fraction $\varphi\left(Z_{i}, t\right)$ increases while technology $Z_{i}$ is at the frontier and subsequently declines when a better technology arrives. Proposition 2 establishes that an equilibrium exists and that all equilibria have the same prices and aggregate quantities.

Proposition 2: Equilibrium with Technological Revolutions. Given the initial condition $M_{0}$ and an increasing sequence $\left\{Z_{i}, t_{i}\right\}_{i=0}^{\iota(t)}$, there exists an equilibrium with

$$
\begin{gathered}
P_{i t}^{M}=\left(\frac{Z_{i}}{Z_{\iota(t)}}\right)^{\frac{1}{\alpha}}, i=0, \ldots, \iota(t), t \geq t_{i} ; \\
M_{i t}=\left\{\begin{array}{ll}
\int_{t_{i}}^{t} e^{-\delta(t-s)} \sigma Y_{s} d s, & t \in\left[t_{i}, t_{i+1}\right) \\
M_{i, t_{i+1}} \cdot e^{-\delta\left(t-t_{i+1}\right)}, & t \geq t_{i+1}
\end{array} ;\right.
\end{gathered}
$$




$$
\begin{gathered}
N_{j t}=\frac{\gamma}{\gamma-1}(1-\eta) ; \\
\varphi\left(Z_{i}, t\right)=\left\{\begin{array}{ll}
0, & t<t_{i} \\
\frac{M_{i t} P_{i t}^{M}}{\sum_{s \geq 0} M_{s t} P_{s t}^{M}}, & t \geq t_{i}
\end{array}, i=0, \ldots, \iota(t) .\right.
\end{gathered}
$$

Aggregation:

$$
\begin{gathered}
Y_{t}=\frac{Z_{\iota(t)}}{N^{\gamma-1}} \cdot\left[M_{t}\right]^{\alpha} \cdot\left[L_{t}\right]^{\nu} \equiv \bar{Z}_{\iota(t)} \cdot M_{t}^{\alpha} \cdot L_{t}^{\nu}, \text { all } t \geq 0, \\
R_{i t}=R_{t}=\frac{\alpha}{\gamma} \frac{Y_{t}}{M_{t}} \quad \text { and } \quad W_{t}=\frac{\nu}{\gamma} \frac{Y_{t}}{L_{t}},
\end{gathered}
$$

where

$$
M_{t}=\sum_{i=0}^{\iota(t)} P_{i t}^{M} M_{i t}
$$

The aggregate equation of motion is

$$
\dot{M}_{t}=\sigma \cdot \bar{Z}_{\iota(t)} \cdot\left[M_{t}\right]^{\alpha} \cdot\left[L_{t}\right]^{\nu}-\delta \cdot M_{t}
$$

Any equilibrium has the same $P_{j t}, P_{i t}^{M}, M_{t}, M_{i t}, N_{j t}, \varphi(\cdot), Y_{t}, Y_{j t}, y_{f j t}, l_{f j t}, R_{i t}, R_{t}$ and $W_{t}$. Proof: See Appendix.

Aggregate output depends on capital stocks of different vintages only through their aggregate market value. Aggregation result (11) implies that even with a series of technological revolutions, the aggregate dynamics of the model follow (7) between changes in $Z$. Specifically, starting from a given $M_{0}$, we can solve (14) on each $\left(t_{i-1}, t_{i}\right)$, using the terminal value $M_{t_{i}}$ from one interval as the initial condition for $M_{t}$ on the next. Figure 1 illustrates the time series outcomes of the model. The economy starts with technology $Z_{0}$. If there were no further technological revolutions, the economy would eventually converge to the balanced growth path $Y_{0}^{\infty}$, as described in Section 2.1. At date $t_{1}$, a new technology $Z_{1}$ arrives, which leads to abrupt obsolescence of all existing capital and a fall in the stock market (see lower left panel of figure 1). Subsequently the economy converges toward a new balanced growth path $Y_{1}^{\infty}$, until this convergence is interrupted by another revolution at $t_{2}$, etc.

It is useful to compare figure 1 with the time paths for the same variables in a model where embodied technological change is exponential. For example, in the Solow (1960) model $M_{t}$ would continuously approach a balanced growth path, and the price of old capital would fall exponentially at a rate that is proportional to the rate of embodied technical progress. 

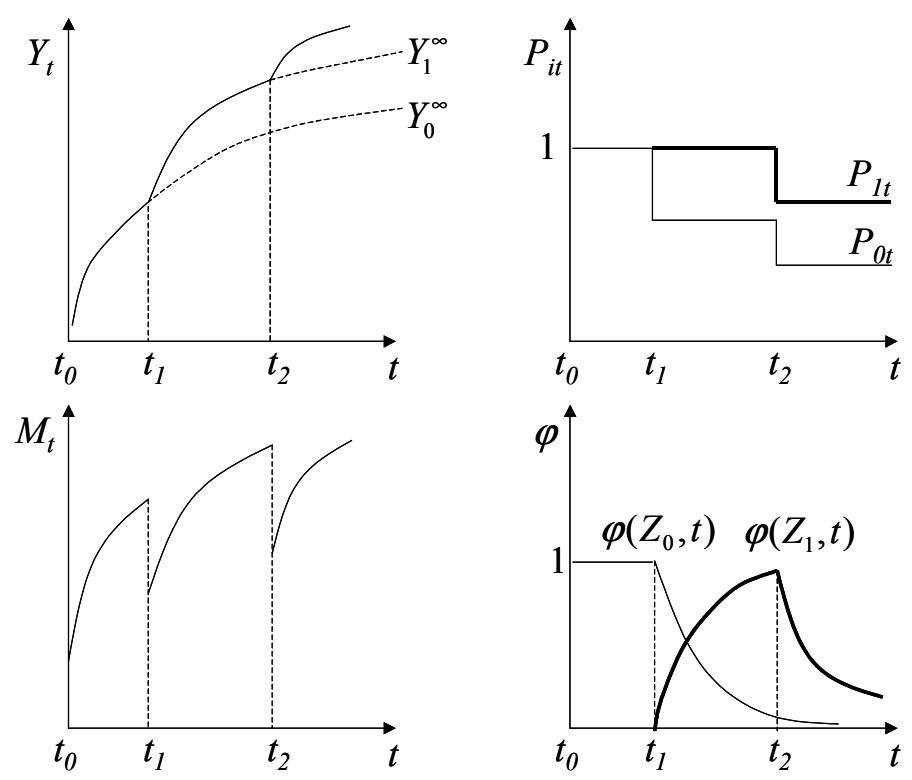

Figure 1: Time series outcomes of the model.

The lower right panel of figure 1 depicts the diffusion curves for technologies $Z_{1}$ and $Z_{0}$. While $Z_{i}$ is the frontier technology, the capital stock that embodies it grows, and (10) implies that $\varphi\left(Z_{i}, t\right)$ grows as well. At date $t_{i+1}, Z_{i}$ is no longer a frontier technology, so investment in capital $M_{i}$ stops. Thereafter, obsolescence and investment in more modern vintages cause $\varphi\left(Z_{i}, t\right)$ to fall.

Along the equilibrium path, there is an on-going reallocation of used capital across firms. This occurs because the old, less productive, capital must become concentrated in the hands of progressively fewer firms, in order for them to earn the same profit as firms with the most up to date capital. Because we assume free entry and frictionless resale of capital goods, our model does not predict whether reallocation of capital happens via mergers or entry and exit: both are consistent with equilibrium behavior (for a model that can discriminate between capital reallocation by exit and by acquisition, see Jovanovic and Rousseau, 2002).

\subsection{Continuous technological change}

The results of Lemma 2 and Proposition 2 hold regardless of the total number of different technologies $Z_{i}$, and none of the equilibrium conditions are intertemporal; therefore, our framework is fully consistent with any increasing time path for the frontier technology, $Z(t)$, continuous or otherwise. As an important special case that maps our framework into existing models of embodiment, we give a detailed description of $Z(t)$ which is piecewise exponential.

Starting with an increasing sequence $\left\{Z_{i} t_{i}\right\}_{i=0}^{\infty}$, define

$$
g_{i} \leq \frac{1}{t_{i+1}-t_{i}} \ln \left(\frac{Z_{i+1}}{Z_{i}}\right)
$$

to be the rate of embodied technological change on the interval $\left[t_{i}, t_{i+1}\right)$. Accordingly, let

$$
Z(t)=Z_{i} e^{g_{i}\left(t-t_{i}\right)}, t \in\left[t_{i}, t_{i+1}\right)
$$

When (15) holds with equality, $Z$ evolves continuously — though different epochs may have different growth rates. When (15) is a strict inequality, $Z(t)$ combines exponential growth with technological 
revolutions at dates $t_{i}$. Solow (1960) is a special case of this formulation with $t_{1}=\infty$ and $g_{0}$ constant forever.

The mathematics of Section 2.2 carry over. In particular, the equilibrium conditions underlying pricing rule (8) hold at any point in time: if $P_{v t}^{M}$ is the price of capital of vintage $v$ at time $t \geq v$,

$$
P_{v t}^{M}=\left(\frac{Z(v)}{Z(t)}\right)^{\frac{1}{\alpha}}
$$

The arguments for the existence and uniqueness of equilibrium are virtually unchanged as well, with integrals replacing the summation signs in (10) and (13), and with $M_{v t}=\sigma Y_{t} e^{-\delta(t-v)}$ replacing (9). The analog of (14) is

$$
\dot{M}_{t}=\bar{Z}(t) \cdot M_{t}^{\alpha} \cdot L_{t}^{\nu}-\left(\delta+\frac{g_{i}}{\alpha}\right) M_{t}, t \in\left[t_{i}, t_{i+1}\right) .
$$

The extra depreciation term $\frac{g_{i}}{\alpha}$ reflects the fact that the price of capital goods falls at a rate of $\frac{g_{i}}{\alpha}$ on the interval $\left[t_{i}, t_{i+1}\right)$.

The next section estimates the parameters of our model. Section 4 then attempts to use the estimates to evaluate the significance of the information technology revolution in overall productivity change for the post-war U.S. economy.

\section{Estimation}

\subsection{National accounts and intangible capital}

To take our model to data, we must establish the correspondence between variables in the model and those in the NIPA. A preliminary step is to distinguish between intangible and tangible capital.

We think of intangible capital as consisting of proprietary applied knowledge, such as firmspecific human capital, particular production techniques, product designs, etc. We think that intangible capital is a non-rival good, which may contribute to internal increasing returns to scale. Firms can either rent applied knowledge from consultants, or, more likely, invest in it themselves but they can sell the undepreciated portion of it in the future, just as they can resell undepreciated physical capital. Suppose that intangible capital embodies a technology in the same way as physical capital, with the same current technology available in every period for tangible and intangible investment, and suppose that aggregate output $Y_{t}$ divides homogeneously into intangible and tangible investment, as well as consumption.

Let us also assume that the value of intangible capital is a constant fraction $\theta$ of the overall capital stock, where $\theta$ is a parameter to be estimated. ${ }^{1}$ Let

$$
M_{t}=A_{t}+K_{t}
$$

with

$$
A_{t}=\theta M_{t}, K_{t}=(1-\theta) M_{t}
$$

\footnotetext{
${ }^{1}$ Under these assumptions, our results will carry over if the firms have a production function $y=Z a^{\alpha} k^{\beta} l^{\nu}$ and choose $a, k$ and $l$ to maximize profit. Then, in equilibrium, $\theta=\alpha /(\alpha+\beta)$. See Laitner and Stolyarov (2002) for details.
} 
If physical and intangible capital depreciate at roughly equal rates, then the market clearing condition for output is ${ }^{2}$

$$
\sigma Y_{t}=\dot{A}_{t}+\delta A_{t}+\dot{K}_{t}+\delta K_{t}=I_{A t}+I_{K t} .
$$

It immediately follows from (17) that investments in intangible and physical capital are constant fractions of output:

$$
I_{A t}=\theta \sigma Y_{t} \text { and } I_{K t}=(1-\theta) \sigma Y_{t} .
$$

While the model's output, $Y_{t}$, then includes investment in intangible capital, national accounts typically classify such investments as intermediate goods (see, for example, Howitt, 1996). Thus, the conventional measure of aggregate output, which we label $G D P^{*}$, is the difference between our $Y_{t}$ and intangible investment:

$$
G D P_{t}^{*}=Y_{t} \cdot(1-\theta \sigma)
$$

\subsection{Quality-adjusted price of investment}

With each subsequent change in technology, one unit (one dollar) of consumption good spent on investment buys a unit of capital that embodies a more productive technology. According to (8), the consumption good price of a constant-quality capital good falls over time. Let us fix an arbitrary vintage $v$ and measure the effective quantity of capital in constant-quality units of $M_{v}$. In particular, define one efficiency unit to be the amount of capital that can produce as much output as one unit of capital of vintage $v$ when combined with the same quantity of labor. Let $p_{t}^{e}$ be the amount of consumption good that must be sold at time $t$ in order to purchase one efficiency unit of capital. To compute $p_{t}^{e}$, we must equate outputs from one unit of vintage $v$ capital and $p_{t}^{e}$ dollars worth of frontier vintage $-t$ capital. Thus,

$$
p_{t}^{e}=\left(\frac{Z(v)}{Z(t)}\right)^{\frac{1}{\alpha}} \text { all } t>v
$$

The level of $p_{t}^{e}$ has no meaning, because it depends on the choice of efficiency units, but the rate of change in $p_{t}^{e}$ on any interval $[t, t+\Delta t]$ is proportional to the rate of change in $Z$ :

$$
\ln \left(\frac{p_{t+\Delta t}^{e}}{p_{t}^{e}}\right)=-\frac{1}{\alpha} \ln \left(\frac{Z(t+\Delta t)}{Z(t)}\right) .
$$

The above expression relates the rate of embodied technological progress to the rate of change in the quality-adjusted relative price of investment goods. One way to measure $Z$ is from (20), if we have observations on $p_{t}^{e}$. Gordon's (1990) price series offers a possible set of such observations see Section 3.4 below.

\footnotetext{
${ }^{2}$ Dividing US. National Income and Product Account annual depreciation of nonresidential fixed capital by the sum of physical nonresidential fixed capital and business inventories yields an average of .0589 for 1954-99. Jones and Williams (1995) suggest an average of 0.10 for the depreciation rate on applied knowledge. Estimates of the depreciation of monopoly profits from patents range from 4 to 25 years - see Pakes and Schankerman (1984), Mansfield et al. (1981) and Caballero and Jaffe (1993). Roughly equal rates are presumably not a mere coincidence: if technology is embodied in physical capital, producers would logically design capital goods to last as long as a technology typically does.
} 


\subsection{The process for the basic technology}

We estimate/calibrate parameter values using U.S. data from 1953-1995. We exclude the data for 1996-2001, because exogenous information suggests that market values may have been experiencing a bubble in the late 1990s. ${ }^{3}$ Our procedure assumes one drastic change in the economy's basic technology during the entire period. We think the change occurred between 1972 and 1974 and corresponded to the information technology revolution, which became possible with the invention of the microprocessor. There may have been other, minor technological changes as well, and we allow continuous embodied progress in the spirit of Solow (1960) to capture these. Our most general model of TFP is

$$
Z(t)= \begin{cases}Z_{0} e^{g_{0}(t-1953)}, & t<t_{1} \\ Z_{1} e^{g_{1}\left(t-t_{1}\right)}, & t \geq t_{1}\end{cases}
$$

with

$$
\begin{gathered}
Z_{1} \geq Z_{0} e^{g_{0}\left(t_{1}-1953\right)}, \\
g_{0} \geq 0, g_{1} \geq 0 .
\end{gathered}
$$

With the above constraints $Z(t)$ is non-decreasing. Parameters $g_{0}$ and $g_{1}$ characterize the flow embodied technological change, and the difference between $Z\left(t_{1}+0\right)$ and $Z\left(t_{1}-0\right)$ measures the extent of revolutionary change.

\subsection{Calibration/estimation}

This section describes our procedure for calibrating the model. As stated, we assume - on the basis of existing work by historians and others - that a transforming technological revolution occurred at $t_{1} \in\{1972,1973,1974\}$. The parameters which we calibrate are $\alpha, \theta, \nu, Z_{0}, Z_{1}, g_{0}, g_{1}, \sigma$, and $\delta$. They constitute a vector $\vec{u}^{4}$

The results of Section 2 do not depend on whether or not $L_{t}$ grows at a constant rate, and henceforth we take $L_{t}$ to be an exogenous function of time. We provide two different measurements of it. The first is NIPA labor hours (normalized to 1 in 1954). ${ }^{5}$ The second is the product of the first and a quality index for private labor input from Ho and Jorgenson. ${ }^{6}$ The "quality" index corrects for changes in age, sex, education, and class of employment (i.e., self-employed or wage/salary).

For the estimation, we use a discrete-time version of our model, which matches annual data. Note that the variable $M_{t}$ measures end-of-year net worth, hence the level at the start of year $t+1$. The difference version of (16) is

$$
M_{t}=m\left(M_{t-1}, t\right) \equiv \sigma \cdot \bar{Z}_{t} \cdot\left[M_{t-1}\right]^{\alpha} \cdot\left[L_{t}\right]^{\nu}+\left(1-\delta-\frac{g_{i}}{\alpha}\right) \cdot M_{t-1} .
$$

The equations of our statistical model have the form

$$
f_{t}^{i}=\epsilon_{t}^{i}, \quad i=1, \ldots, 7 .
$$

\footnotetext{
${ }^{3}$ When we include 1996-2001 market values and rates of return into the estimation and test whether the data from this time period is consistent with the parameters estimated using just 1953-1995 time series, the test strongly rejects. Also, the market values from 2001 on came back in line with parameter estimates from 1953-1995 data. See Laitner and Stolyarov (2002, Table 4) for more details.

${ }^{4}$ Notice that our empirical analysis will not separately identify $N$.

${ }^{5}$ NIPA table 6.9B, row 2. See http://www.bea.doc.gov/bea/dn1.htm. This measures annual hours of full and part-time employees of domestic industries in the U.S.

${ }^{6}$ See Mun S. Ho and Dale Jorgenson, "The Quality of the U.S. Workforce 1948-95," updated tables through 1999, http://post.economics.harvard.edu/faculty/jorgenson/papers/papers.html.
} 
In each case, $f_{t}^{i}$ gives, as described below, the discrepancy between a current dependent variable and a function, which the theoretical model determines, of exogenous variables, past dependent variables, and parameters. $\epsilon_{t}^{i}$ is a regression error.

We assume that the instant after the revolution of $t_{1}$, the resale value of existing capital falls according to (8). Using that formula, define

$$
\tilde{M}_{t}=\left\{\begin{array}{ll}
M_{t}\left(\frac{Z_{0}}{Z_{1}}\right)^{\frac{1}{\alpha}} & t=t_{1} \\
M_{t} & t \neq t_{1}
\end{array} .\right.
$$

Then our regression equations are as follows:

$$
\begin{gathered}
f_{t}^{1} \equiv \ln \left(M_{t}\right)-\ln \left(m\left(\tilde{M}_{t-1}, t\right)\right), \quad t=1953, \ldots, 1996 . \\
f_{t}^{2} \equiv \ln \left(G D P_{t}^{*}\right)-\ln \left((1-\theta \cdot \sigma) \cdot \bar{Z}_{t} \cdot\left[\tilde{M}_{t-1}\right]^{\alpha} \cdot\left[L_{t}\right]^{\nu}\right), \quad t=1953, \ldots, 1996 \\
f_{t}^{3} \equiv \ln \left(I_{K t}\right)-\ln \left((1-\theta) \cdot \sigma \cdot \bar{Z}_{t} \cdot\left[\tilde{M}_{t-1}\right]^{\alpha} \cdot\left[L_{t}\right]^{\nu}\right), \quad t=1953, \ldots, 1996 \\
f_{t}^{4} \equiv \frac{W_{t} \cdot L_{t}}{G D P_{t}^{*}}-\left(1-\tau_{t}\right) \cdot \frac{\nu}{\gamma(1-\theta \cdot \sigma)}, \quad t=1953, \ldots, 1996 . \\
f_{t}^{5} \equiv \ln \left(D_{t}\right)-\ln \left(\bar{\delta} \cdot(1-\theta) \cdot \tilde{M}_{t-1}\right), \quad t=1953, \ldots, 1996 . \\
\left.f_{t}^{6} \equiv r_{t}-\left[\left(1-\tau_{t}\right) \cdot \frac{\alpha}{\gamma} \cdot \bar{Z}_{t} \cdot\left[\tilde{M}_{t-1}\right)\right]^{\alpha-1} \cdot\left[L_{t}\right]^{\nu}-\Delta_{t}\right], \quad t=1953, \ldots, 1996
\end{gathered}
$$

where $\Delta_{t}$ is physical depreciation plus the capital loss from obsolescence:

$$
\begin{gathered}
\Delta_{t}= \begin{cases}\delta+\frac{1}{\alpha} g_{0}, & \text { if } t<t_{1} \\
\delta+\frac{1}{\alpha} g_{1}+\left[1-\left(\frac{Z_{0}}{Z_{1}}\right)^{\frac{1}{\alpha}}\right], & \text { if } t=t_{1} \\
\delta+\frac{1}{\alpha} g_{1}, & \text { if } t>t_{1}\end{cases} \\
f_{t}^{7}=\ln \left(\frac{p_{t+1}^{e}}{p_{t}^{e}}\right)+\frac{1}{\alpha} \ln \left(\frac{Z(t+1)}{Z(t)}\right), t=1953, \ldots, 1983 .
\end{gathered}
$$

Appendix 1 lists our data sources. As stated, (R1) comes from (14). Notice that since $f_{t}^{1}$ is a difference of logarithms, there is no reason to think of $\epsilon_{t}^{1}$ as having a time trend - it equals the $\log$ of the ratio of actual to predicted $M$. The same logic applies for the second, third, and fifth equations below.

Equation (R2) comes from (19): the left side is the log of the flow of GDP (omitting residential housing services) - see Appendix 1; the right side is the cumulative flow of the model's prediction of the same.

Equation (R3) comes from (18). In (R4), factor payments to labor, as a fraction of $G D P^{*}$, are equated to the same from the model. Before doing so, we introduce indirect business taxes, which affect the marginal revenue products of inputs. Let $\tau_{t}^{*}$ be the measured indirect tax rate. We set the tax rate $\tau_{t}=\tau_{t}^{*} \cdot(1-\theta \cdot \sigma)$ in (R4) to make tax collections $\tau_{t} \cdot Y_{t}$ match NIPA tax collections $\tau_{t}^{*} \cdot G D P_{t}^{*}$.

In (R5), $D_{t}$ is the annual flow of NIPA depreciation. The latter includes both physical deterioration and declining resale value due to obsolescence. Therefore, on the right side of (R5), $\bar{\delta}$ combines 
physical deterioration and obsolescence - from both continuous and revolutionary technological change. The counterpart of the long-run average depreciation rate in our model is the physical depreciation rate $\delta$ plus the average rate of obsolescence from flow embodied technical progress and technological revolutions. Accordingly, we set

$$
\bar{\delta} \equiv \delta+\frac{1}{\alpha}\left[g_{0}\left(\frac{t_{1}-1953}{1995-1953}\right)+g_{1}\left(\frac{1995-t_{1}}{1995-1953}\right)\right]+\frac{1}{T}\left[1-\left(\frac{Z\left(t_{1}-0\right)}{Z\left(t_{1}+0\right)}\right)^{\frac{1}{\alpha}}\right],
$$

where $T$ is the average interval between major technological revolutions. We set $T$ from longterm data on revolutionary inventions. For example, Cohen et al. [2000, p.30] list 5-7 distinct revolutionary inventions over the last 200 years. This suggests a value of $T$ between 30 and 40 . We experimented with values of $T$ between 30 and 50 and found that our results are essentially unchanged. Longer term stock market data seem to be consistent with the same values of $T$ : during the 20th century there were three major market declines of roughly the same magnitude: in 1916, 1929 and 1972. Accordingly, we set $T=30$ (see Laitner and Stolyarov (2002)).

Note we do not use the NIPA capital stock series. It is constructed using a depreciation rate that is constant over time. This misses the unevenness of obsolescence, especially during episodes of revolutionary change (see Laitner and Stolyarov (2002)).

Equation (R6) incorporates data on the empirical rate of return on financial investments, $r_{t}$. The latter comes from ex post returns - see Appendix 1. The right side of (R6) comes from Lemma 1: it is the model's average rate of return, including capital losses, during year $t$.

Equation (R7) matches the decline in the quality-adjusted relative price of private non-residential investment with its counterpart in the model, according to (20). The quality adjusted equipment price index is available from 1953 to 1983, and we only use equation (R7) for this subperiod. See Appendix 1 for details.

We estimate (R1)-(R7) from a collection of first moments,

$$
\mu(\vec{u})=\frac{1}{1995-1953} \cdot \sum_{t=1953}^{1995}\left(\begin{array}{c}
f_{t}^{1} \cdot v_{t}^{1} \\
\cdots \\
f_{t}^{7} \cdot v_{t}^{7}
\end{array}\right)
$$

where $v_{t}^{i}$ is a vector of ones and zeros. ${ }^{7}$

The vector $v_{t}^{i}$ is the same for equations (R1)-(R2), and (R6) - having six elements. The first element is 1 for $t<t_{1}$, and 0 otherwise; the second is 1 for $t \geq t_{1}$, and 0 otherwise; the third is 1 for first and third thirds of of the time interval before $t_{1}$, and 0 elsewhere; the fourth is 1 for the first third and -1 for the third, and 0 elsewhere; the fifth is 1 for the first and third thirds of the time interval with $t \geq t_{1}$, and 0 elsewhere; and, the sixth is 1 for the first third and -1 for the third, and 0 elsewhere. The rationale is as follows. We think of our data as forming a panel of episodes $\left[t_{i}, t_{i+1}\right), i=0,1, \ldots$. Econometrically, we think of the length of each episode as very long. Our period of analysis includes two episodes. The first two elements of $v_{t}^{i}$ embody the idea that the mean of $\epsilon_{i T}$ should be 0 over each episode. Beyond that, the model has specific predictions. For example, within an episode, $\ln \left(M_{t}\right)$ should rise rapidly at first, then its rate of increase should diminish as it converges to a steady-state level - recall figure 1. Elements 3-4 and 5-6 allow us to attempt to match such precise patterns.

\footnotetext{
${ }^{7}$ Nonlinear least squares would have a consistency problem from the lagged dependent variable in (R1)-(R2) if $\varepsilon_{1 T}$ and $\varepsilon_{2 T}$ are autocorrelated. Pure calibration (which would roughly correspond to using single-element instruments below, always equaling 1) would not be able to set 9 parameters from 6 equations.
} 
For (R3)-(R4), the model does not make episodic predictions; and, for (R5), the data only reflects average depreciation over entire episodes. Thus, $v_{t}^{i}$ for $i=3,4,5$ has a single element, 1 .

For (R7), we let the first element of $v_{t}^{7}$ be 1 prior to $t_{1}$, and 0 after; the second element is 0 before $t_{1}$, and 1 for $t \geq t_{1}$. In fact, to eliminate possible data irregularities from the Nixon price controls, we set all elements of $v_{t}^{7}$ to 0 for $t \in\{1972,1973,1974\}$.

Our estimation steps follow Gallant (1987, ch.6). Define

$$
S(\vec{u}, V) \equiv[(1995-1953) \cdot \mu(\vec{u})]^{\prime} V^{-1}[(1995-1953) \cdot \mu(\vec{u})] .
$$

We choose parameter values to minimize $S($.$) . There are two stages. In the first, V$ has submatrices

$$
\sum_{t}\left[v_{t}^{i}\right]\left[v_{t}^{i}\right]^{\prime}
$$

along its principal diagonal. Given this $V$, minimizing $S($.$) with respect to \vec{u}$ yields consistent estimates. Using these to evaluate $f_{t}^{i}$, we form an improved estimate $\widehat{V}$ of $V$, which is consistent even with autocorrelated and heteroscedastic errors. The second stage minimizes $S(., \widehat{V})$, yielding our estimator $\widehat{u}$. Finally, we compute the covariance matrix for $\widehat{u}$.

\subsection{Method of moments parameter estimates}

We estimate three specifications of our model. (i) The first one, which we call the "flow model," restricts $Z(t)$ in (21) to be continuous and growing at rate $g_{0}$ before date $t_{1}$ and at rate $g_{1}$ afterwards. We estimate, $g_{0} \geq 0, g_{1} \geq 0$ and $Z_{0} ; Z_{1}$ is pinned down by the constraint

$$
Z_{1}=Z_{0} \cdot e^{g_{0} \cdot\left(t_{1}-1953\right)}
$$

The estimation uses equations (R1)-(R7). (ii) The second specification, which we call the "punctuated model," excludes flow technological progress but allows a discrete step at $t_{1}$. In particular, we set $g_{0}=g_{1}=0$, but estimate $Z_{1}$ subject only to $Z_{1} \geq Z_{0}$. Since an index for investment good prices in efficiency units is likely to be conceptually inconsistent with this formulation, we employ only equations (R1)-(R6). The price effects of embodied technological progress can still be manifest, of course, in the resale value of used capital and ex post financial rates of return — which (R1) and (R6) can capture. Section 4 provides a detailed discussion on the omission of (R7). (iii) The third specification, which we call the "combined model," allows both flow and punctuated technological change: we estimate $g_{0} \geq 0, g_{1} \geq 0$, and $Z_{1}$, subject to the constraint

$$
Z_{1} \geq Z_{0} \cdot e^{g_{0} \cdot\left(t_{1}-1953\right)}
$$

Again, the estimation uses (R1)-(R6).

Table 1 presents our estimates. ${ }^{8}$ As discussed above, we have two labor series. We also estimate conditional on three possible revolution dates $t_{1} \in\{1972,1973,1974\}$; hence, there are 6 sets of

\footnotetext{
${ }^{8}$ Our regression equations involve variables with trend growth, and we therefore need to check if the residuals are growing as well, because this may lead to inconsistent parameter estimates. For all 18 sets of estimates, we perform equation-by-equation autoregressions of residuals as well as the VARs for the whole set of equations. The residuals of equations (R3)-(R5) for the saving share, labor share and average depreciation rate, respectively, have the highest AR coefficients - they are in 0.70-0.92 range for the flow model and in 0.75-0.88 range for the punctuated and combined models. The VARs produce similar results: the largest (by absolute value) eigenvalue of the coefficient matrix is in the 0.90-0.95 range for the flow model, and in the 0.80-0.90 range for the punctuated and combined models.
} 
estimates for each of our three model specifications. The instruments in our method of moments procedure are, as also described above, always vectors of ones and zeros; maintaining the spirit of calibration, we do not employ independent variables or lagged dependent variables as instruments. Nevertheless, the number of instruments exceeds the number of estimable parameters in every case, and Table 1 presents the $\mathrm{p}$-values of chi-squared tests of overidentification restrictions. The tests never reject at the $5 \%$ significance level.

We now present a detailed analysis of our results.

\section{Results}

Continuous Technological Change. We first estimate our model imposing the constraint that $Z$ changes continuously. This specification is a bridge between our analysis and existing studies of embodied technical change such as Greenwood et al. (1997) and Gort et al. (1999). Our estimation uses all seven of Section 3's equations, incorporating Gordon's (1990) quality adjusted price series for producer durable equipment (see Appendix 1).

The conventional approach for measuring the rate of technological progress compares the growth rates of output and inputs. Taking a time derivative of both sides of aggregate production function (11), and using the notation $g_{X} \equiv \dot{X} / X$,

$$
g_{Y}=g_{Z}+\alpha \cdot g_{M}+\nu \cdot g_{L}
$$

There are three ways in which the right-hand side can explain a given growth rate of output: (i) inputs can grow relatively rapidly, (ii) returns to scale - i.e., the sum $\gamma \equiv \alpha+\nu-$ can be relatively high, or (iii) technological progress - i.e., $g_{Z}$ - can be relatively rapid. We have observations on $M$ and two different measures of $L$; our focus is separating the roles of the remaining two elements, returns to scale and technological progress.

With continuous productivity change, basically we have a two-pronged strategy: equation (R2) compares output and input quantities as in (23); equation (R7) compares the rate of technological progress with the rate of decline of quality-adjusted investment good prices as in (20). In words, our theoretical model leads to a primal and a dual framework for pinning down the roles of technological progress and increasing returns to scale. In (23), higher returns to scale reduce the need for positing a high rate of technical progress; conversely, in (20) a higher $\alpha$ requires a higher $g_{Z}$ to match the same price series.

Table 2 presents the estimates. The first three columns employ NIPA labor data; the second three use labor corrected for quality improvements that occur over time. On the grounds of sophistication and economic logic, we prefer the quality adjusted labor series. Each column assumes a specific date $t_{1}=1972$, 1973, or 1974 for the IT revolution.

Table 2's point estimates of aggregate returns to scale (e.g., $\gamma$ ) are all greater than 1. Our quality adjustment to labor makes $g_{L}$ higher, especially prior to 1970, a period when education was growing especially rapidly. Equation (23) implies that faster input growth leaves less of a role for increasing returns and technological progress. Switching from labor series 1 to 2 affects both of the latter: the point estimates of $\gamma$ go down, and the estimates of $g_{0}$ also become smaller and much more similar to $g_{1}$. The estimated rates of change for investment goods prices per efficiency unit $-g_{0} / \alpha$ and $-g_{1} / \alpha$ roughly match the observations, except with labor series 1 and $t_{1}=1972$, where the model picks $g_{0}$ and $g_{1}$ that are too low.

Letting $y$ be the average product of labor (i.e., $y=Y / L$ ), one can rewrite $(23)$ as 


$$
(1-\alpha) \cdot g_{y}=g_{Z}+\alpha \cdot\left(g_{M}-g_{Y}\right)+(\gamma-1) \cdot g_{L}
$$

The terms on the right-hand side correspond to contributions from embodied technical progress, capital deepening, and returns to scale, respectively, and the last three rows of Table 2 provide a productivity decomposition based on these. For quality-adjusted labor, our estimate of the total share of embodied technological change in productivity growth agrees with the $60 \%$ share in Greenwood et al. (1997) and 52\% share in Gort et al. (1999). We differ from the existing studies in our interpretation of the remainder $(1-\alpha) \cdot g_{y}-g_{Z}$. In Greenwood and Gort, the long-run rate of TFP growth equals $(1-\alpha) \cdot g_{y}$. These authors independently estimate $g_{Z}$. But, because they use a balanced growth approximation, they identify the left over $(1-\alpha) \cdot g_{y}-g_{Z}$ as the rate of "neutral" technical progress. In contrast, we set the parameters of our model from the entire time path of macroeconomic variables, and we interpret $(1-\alpha) \cdot g_{y}-g_{Z}$ as a combination of contributions from capital deepening and increasing returns. Even with continuous technological change, it seems plausible that capital deepening was important in the U.S. after WWII and the Great Depression.
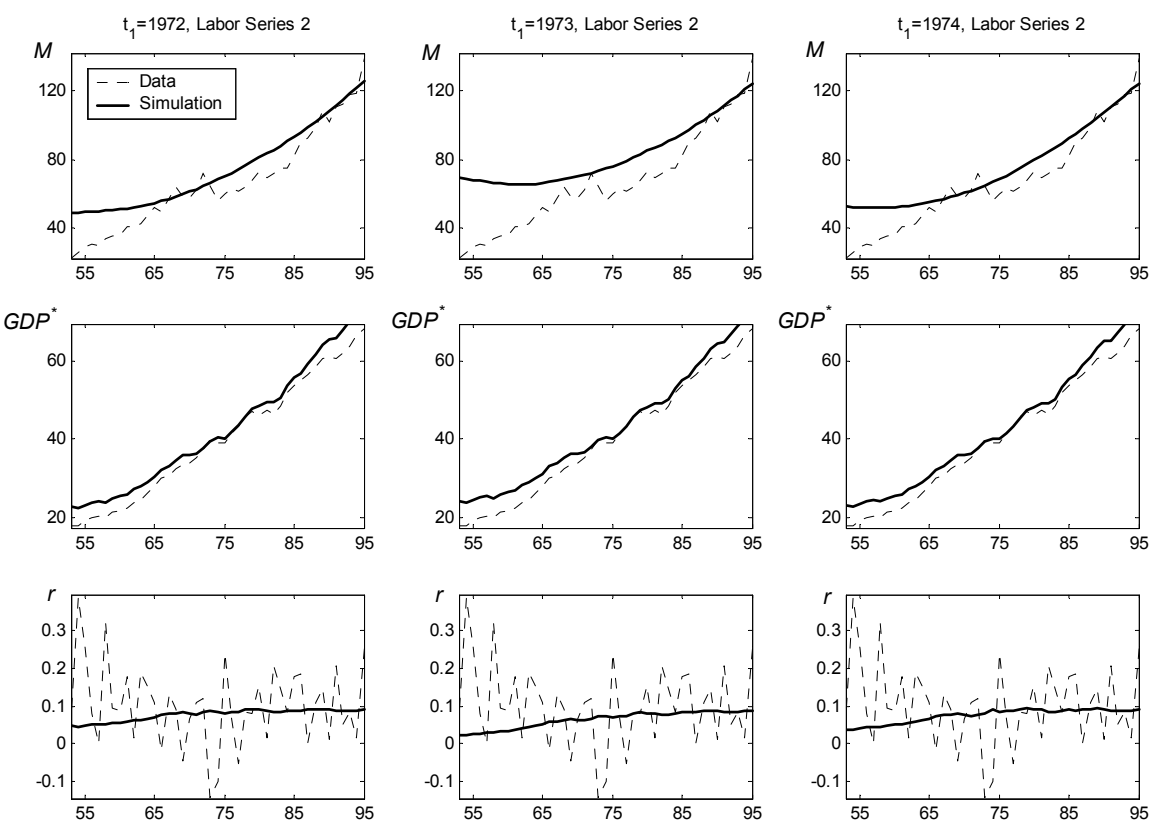

Figure 2: Simulation results, flow model.

Despite its correspondence to the existing literature, we believe the specification with flow embodied technical progress has a number of shortcomings. First, it is inconsistent with abrupt falls in the stock market and sharp variations in the rate of return on financial investments. This inconsistency is manifested on Figure 2 that shows the simulation results for the flow model. We perform dynamic simulations from $t_{1}$ forward to 1995 and backward to 1953 . The model does not track market values, especially in the earlier period, and it cannot produce any sizeable variations in the rate of return. Formally, Table 2 shows that a Lagrange multiplier test of the constraint $Z_{0} \cdot e^{g_{0} \cdot\left(t_{1}-t_{0}\right)}=Z_{1}$ rejects even at a very low significance level. Second, many commentators have written on the significance of the IT revolution and dated it to the early $1970 \mathrm{~s}$, but in all cases the estimated flow rate of technological progress is less after $t_{1}$ than before.

Punctuated Technological Progress. In our second specification, technological progress is punctuated. Discontinuous improvements arrive every 20-40 years at Poisson time intervals, with no technological progress in between. 
The analysis again offers two ways of measuring the rate of technological progress and returns to scale. The "primal" approach based on quantitites — see (R2) — remains as above. Lemma 2, Section 2, provides the "dual" approach by showing that the resale price of used capital should drop after a seminal invention, the decline having a precise relation to the degree of technical progress. Equation (R1) can pick up this second relationship from stock market data, and equation (R6) can do the same from financial rates of return.

From an empirical standpoint, the punctuated specification is potentially attractive in two other ways. First, instead of predicting that the economy will converge to a steady state and subsequently remain in its vicinity, the punctuated model projects a sequence of cycles: a seminal invention leaves the economy significantly below its stationary capital-to-labor ratio, and the economy begins converging toward the higher steady state; each new seminal invention reinitiates the process e.g., Figure 1. The predicted dynamics offer another basis for calibration — indeed Section 3 chose its instruments to take advantage of the detailed implications of Figure 1. Second, empirical studies of the punctuated model can make use of the dates for seminal inventions which historians independently provide.

Unfortunately, conceptually the punctuated model is almost surely inconsistent with Gordon's efficiency-unit-price data. In practice, construction of such indices relies heavily on tracking the nominal prices of sets of goods whose specifications remain the same, yet the punctuated model associates technological progress precisely with the introduction of qualitatively new investment goods. In theory, ad hoc hedonic procedures could lead to accurate measures of investment-good prices per efficiency unit, but that would require enormous sophistication - e.g., Gordon (1990, p. 38-39). As Gordon (1990, p. 96) writes,

"The most important single innovation in the capital goods industry during the postwar period has been the replacement of the clerk working with a calculating machine by the electronic computer. The hedonic technique has been used to evaluate quality improvements in computers, but not to evalute the relative quality of computers and calculating machines."

In fact, one could view our punctuated model as developing its own, exact hedonic index directly from an equilibrium framework. In the end, we estimate the punctuated model from equations (R1)(R6).

Table 3 presents the estimates. Point estimates of $\gamma$ are more narrowly bunched than for Table 2, and their standard errors are slightly smaller. All of the point estimates imply increasing returns to scale, and none of the $95 \%$ confidence intervals include constant returns. The punctuated model imposes constraints $g_{0}=g_{1}=0$. With labor series 2, a Lagrange multiplier test of these restrictions accepts a zero multiplier at the $5 \%$ significance level. (Recall that the flow model, in contrast, rejected the constraint imposing continuity at $t_{1}$ ).

With labor series 2, our estimates of $\gamma$ range from 1.09 to 1.11. They are close to corresponding estimates from the flow model reported in Table 2. The confidence intervals include the 1.01-1.03 range from aggregate returns to scale reported in Basu and Fernald (1997). Data on price markups offer an independent source of evidence: in our model, the markup equals $\gamma$ (see Lemma 1); for comparison, Jones and Williams (2000) suggest that empirical markups range from 1.05-1.4. ${ }^{9}$

Across our preferred estimates, the upper end of the confidence interval for $\gamma$ is no more than 1.20, which we suggest as an upper bound on aggregate returns to scale. This upper bound is of separate interest in macroeconomics. Apart from productivity measurement, it is important

\footnotetext{
${ }^{9}$ See also Basu (1993) and Norribn (1993).
} 
for evaluating the empirical relevance of existing growth models. Many macroeconomic models rely on some minimum degree of increasing returns to generate qualitatively new results, such as indeterminacy in one-sector growth models (e.g., Farmer and Guo, 1994; Schmitt-Grohe, 1995), or rising real wages with government purchases (Rotemberg and Woodford, 1992). ${ }^{10}$

Integrating both sides of (24) from $t_{0}=1953$ to $t_{2}=1995$ (with a Stieljes integral),

$$
(1-\alpha) \ln \left(\frac{y_{2}}{y_{0}}\right)=\ln \left(\frac{Z_{2}}{Z_{0}}\right)+\alpha \cdot\left[\ln \left(\frac{M_{2}}{M_{0}}\right)-\ln \left(\frac{Y_{2}}{Y_{0}}\right)\right]+(\gamma-1) \cdot \ln \left(\frac{L_{2}}{L_{0}}\right) .
$$

Table 3 shows a productivity decomposition based on the right-hand side of (25). In the calculations, the only event associated with investment specific technical progress is the IT revolution. With our preferred estimates, roughly 40\% of overall productivity growth during 1953-1995 came from the IT revolution, $35 \%$ came from capital deepening, and $25 \%$ resulted from increasing returns to scale.
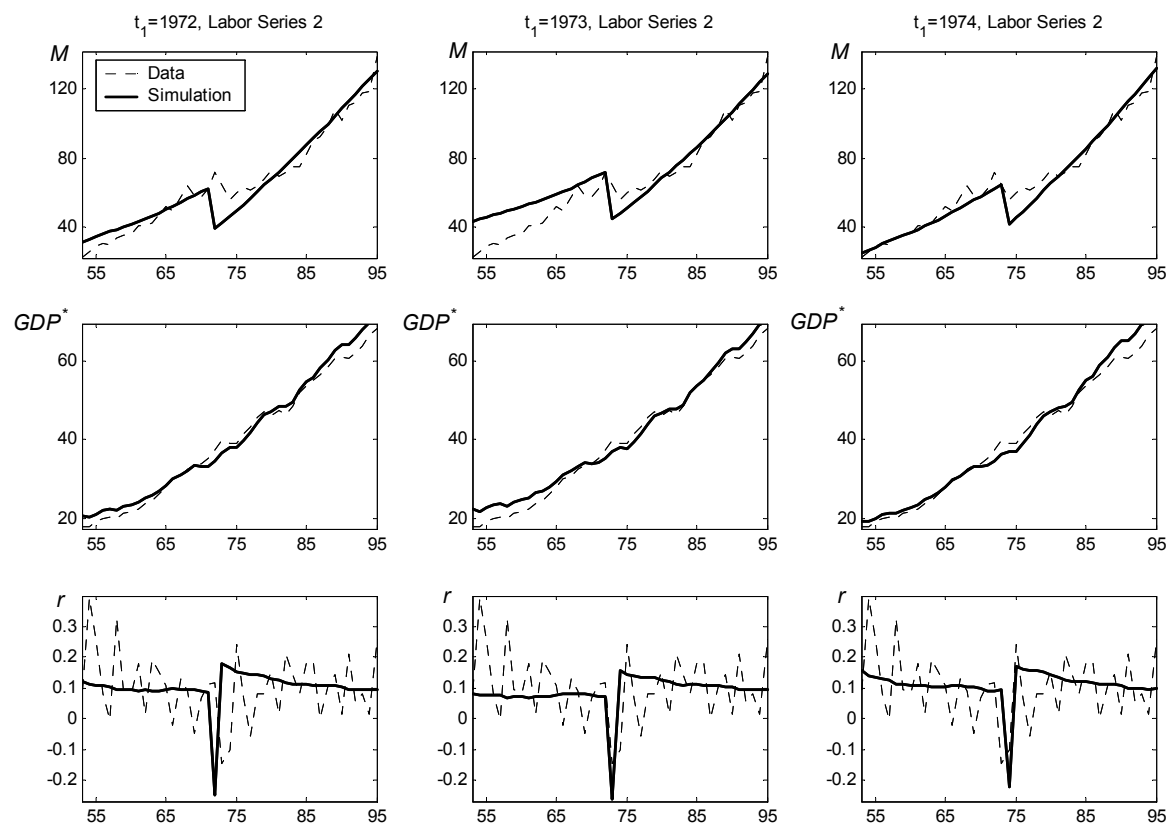

Figure 3: Simulation results, punctuated model.

The punctuated model has the advantage of being able to explain the stock market decline of the early 1970s. Figure 3 shows simulations of the punctuated model with labor series 2 . For revolution dates $t_{1}=1972$ and 1974, simulations of $M, G D P^{*}$, and $r$ fit the data well; these are by far the best simulations that any of the estimates in Table 1 produce. $^{11}$

The punctuated model is in full agreement with the idea of productivity enhancements from the IT revolution: Table 3 shows abrupt productivity growth at $t_{1}$ of $17-18 \%$ for labor series 2 .

As indicated above, by nature the model disagrees with Gordon's price data; the model predicts the relative price of investment goods will follow a step pattern - constant until $t_{1}$, dropping

\footnotetext{
${ }^{10}$ On the other hand, multisector models can generate indeterminacy with relatively small increasing returns (Benhabib and Farmer, 1996; Perli, 1995) and this can follow even with firm-level decreasing returns but aggregate constant returns (e.g., Benhabib, Meng, and Nishimura, 2000).

${ }^{11}$ While the model overpredicts the stock market decline - the predictions for labor series 2 in Table 2 being $40-$ $43 \%$, and the actual decline being $22 \%$ - our Flow of Funds data for $M$ includes noncorporate as well as corporate business, and noncorporate values may be less accurate. Our rate of return data, on the other hand, comes exclusively from corporations. This data shows exceptional declines for two consecutive years, and the sum of the two declines closely matches the simulation's single negative return.
} 
abruptly at $t_{1}$, and then constant until 1995. Nevertheless, we can compare total effects. Gordon's data show an average fall in the relative price of nonresidential investment goods of about $2.2 \%$ annually. From 1953-83, the total drop is then 48\%. With labor series 2, Table 3 implies that the decline over the same period in the price per efficiency unit of investment is $40-43 \%{ }^{12}$
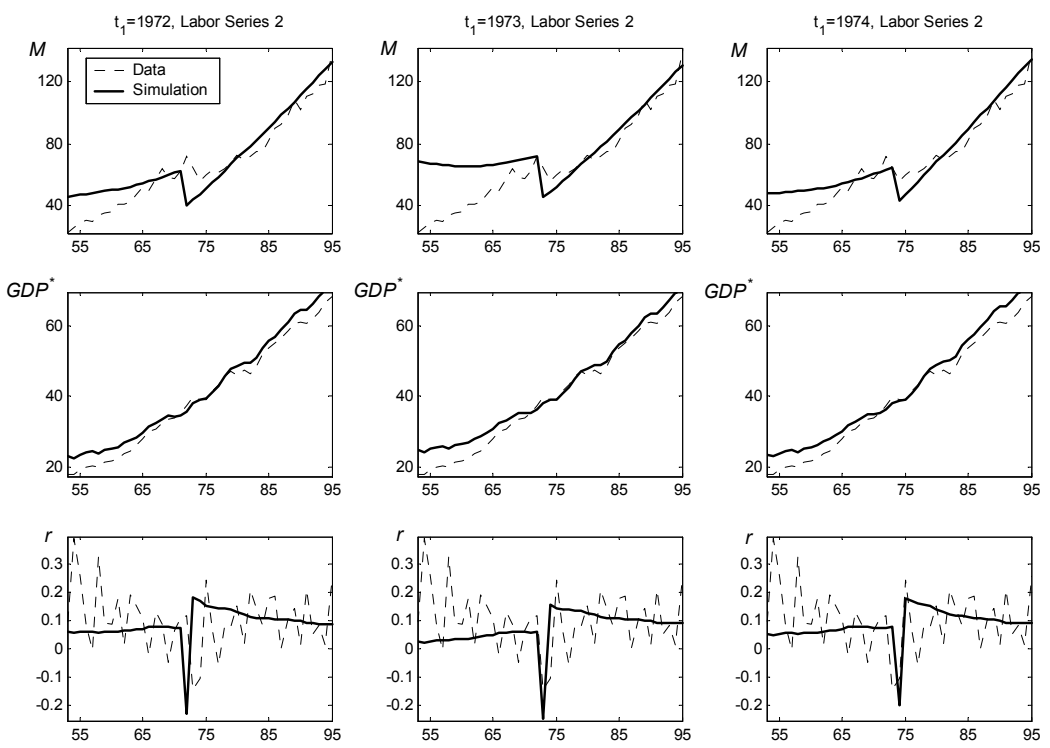

Figure 4: Simulation results, combined model.

Combined Model. We can estimate general specification (21) combining punctuated and flow embodied technological change. We assume a revolution at $t_{1}$ and flow change before and after the same date, the latter at rates $g_{0}$ and $g_{1}$, respectively. We impose the constraints that $Z(t)$ be nondecreasing and that $\gamma \geq 1$. As argued above, conventional hedonic price indices are likely to be inconsistent with discontinuous changes in technology; therefore, we estimate the combined model with six equations (R1)-(R6).

Table 4 shows our results. The estimates of aggregate returns to scale are somewhat lower than Tables 2-3, and constant returns are never rejected. At a 5\% significance level, a Wald test rejects simplification to either the punctuated model (i.e., $g_{0}=0=g_{1}$ ) or the flow model (i.e., $\left.Z_{0} \cdot e^{g_{0} \cdot\left(t_{1}-t_{0}\right)}=Z_{1}\right)$. However, the estimated magnitude of the IT revolution, $Z_{1} /\left(Z_{0} \cdot e^{g_{0} \cdot\left(t_{1}-t_{0}\right)}\right)$, remains almost as large (i.e., 14-17\%) as for the punctuated model. For labor series 2, the average rate of decline of investment prices 1953-83 (see the discussion above) roughly matches the Gordon index's annual rate of change of $-2.2 \%$.

In terms of productivity decomposition, Table 4's shares of the IT revolution and of capital deepening are similar to those for the punctuated model, especially for estimates based on labor series 2. Flow technological change inherits much of the former share of increasing returns, however. Averaging shares over cases with labor series 2 yields the following decomposition for the combined framework: $38 \%$ of overall growth in the average product of labor is due to the IT revolution, $26 \%$ is due to other embodied technological progress, $34 \%$ is due to capital deepening, and $2 \%$ is attributed to increasing returns to scale.

Figure 4 shows the simulation results for the combined model. As expected, simulation results are better than those on Figure 2. Perhaps more unexpectedly, the simulations of the punctuated

\footnotetext{
${ }^{12}$ Notice that 1953-83 coincidentally corresponds to the average duration of one revolutionary cycle in the U.S., which Section 3 estimated to be 30 years.
} 
model on Figure 3 still produce a much better fit for the $M$ and $G D P^{*}$ data.

Discussion Tables 2-4 and Figures 2-4 suggest the following summary observations. (i) Although labor quality issues are not the primary topic of this paper, one's choice of labor series makes a big difference to one's estimate of $\gamma$ in Tables 2-4. (ii) Our preferred formulation is one with punctuated technological progress alone. Lagrange multiplier tests accept this specification; it yields excellent dynamic simulations, whereas the other models do not; it is consistent with, and offers an explanation of, the stock market decline of the early 1970s; and, it bears out the popular notion of an information technologies revolution - perhaps based on the microprocessor - in the U.S. economy beginning in the early 1970s. The flow model, in contrast, is inconsistent with the stock market decline and shows no evidence of an IT revolution - indeed it seems to imply that technological progress slowed down after 1970. Our combined model attributes a larger share of its growth decomposition to punctuated than continuous change, and its quantitative assessment of the IT revolution agrees with the punctuated model. Although a Wald test on the combined model rejects specialization to the punctuated model, most of the conflict appears to lie in the pre $-1970 \mathrm{~s}$ period. Perhaps incorporation of several (smaller) revolutions preceding 1970, based on organic chemicals and/or mainframe computers (i.e., Mowery and Rosenberg, 1998), would eliminate the rejection. (iii) All of the models point to rather modest degrees of increasing returns to scale in the aggregate, with point estimates for $\gamma$ lying between 1.00 and 1.11 for labor series 2 .

Finally, (iv) the growth decompositions for all of the models suggest an important role for capital deepening. In the very long run, capital deepening should have zero average contribution to growth. Nevertheless, for our sample period the share of capital deepening is one quarter to one third. Our analysis therefore provides a warning that a balanced growth approximation may not be very accurate.

\section{Conclusion}

We develop a new way to decentralize an economy with aggregate increasing returns to scale. Although the treatment of constant returns and increasing returns economies in the growth literature has been somewhat separate, our approach treats both within a unified framework. The classic Solow (1960) modelis a special case of ours. More importantly, we show that the aggregation properties that made Solow's model suitable for growth accounting carry over to our setting with increasing returns to scale and discontinuous embodied technological change.

Increasing returns require imperfect competition, and our model has two implications about industrial organization: our equilibrium requires a constant markup of price over marginal cost, and the equilibrium implies a constant number of oligopolists per industry over time. As a depiction of the U.S. economy, a model with oligopoly and a constant concentration arguably has more appeal than one based on monopolistic competition or pure monopoly. ${ }^{13}$

We use our model to provide a new methodology for disentangling TFP growth and returns to scale. Whether technological change is continuous or punctuated, we can use two types of data at the same time: our model characterizes technological progress and returns to scale in terms of the relation of quantities of inputs and outputs and in terms of changes in the price of old capital or new investment goods per efficiency unit. When technological progress is discontinuous, our model

\footnotetext{
${ }^{13}$ For example, Scherer (1990, Table 3.7 and p.82) infers that "something on the order of half of all U.S. manufacturing industries can be characterized as oligopolies." Similarly, Shepherd (1972) concludes that about half of manufacturing value added comes from industries that are "tight oligopolies." Moreover, as would be consistent with our model, Scherer finds little empirical evidence of trend: the proportion of manufacturing value added coming from industries with a four-firm concentration ratios above $50 \%$ is $35.3 \%$ for $1947,39.2 \%$ for 1972 , and $37.1 \%$ for 1982 .
} 
provides additional predictions about non-steady state behavior. We believe that we can estimate returns to scale more precisely than existing approaches based on production function regressions alone. The estimates we favor set the aggregate output elasticity for the U.S. at about 1.1. 


\section{References}

[1] Basu, S., Fernald, J. G., 1997. Returns to Scale in U.S. Production: Estimates and Implications, Journal of Political Economy 105, 249-83.

[2] Basu, S., Fernald, J. G., 1995. Are Apparent Productive Spillovers a Figment of Specification Error?, Journal of Monetary Economics 36, 165-88.

[3] Basu, S., 1993. Procyclical Productivity: Overhead Inputs or Cyclical Utilization?, The University of Michigan, mimeo.

[4] Benhabib, J., Meng, Q., Nishimura, K., 2000. Indeterminacy under Constant Returns to Scale in Multisector Economies, Econometrica 68, 1541-48.

[5] Benhabib, J., Farmer, R. E. A., 1996. Indeterminacy and Sector-Specific Externalities, New York University C.V. Starr Center Economic Research Report: 9612.

[6] Caballero, R. J., Lyons, R. K., 1992. External Effects in U.S. Procyclical Productivity, Journal of Monetary Economics 29, 209-25.

[7] Cohen, S., DeLong, J. B., Zysman, J., 2000. Tools for Thought: What Is New and Different About the E-conomy, University of Berkeley, mimeo, http://econ161.berkeley.edu/OpEd/virtual/technet/Tools_for_Thought.doc

[8] Dixit, A. K., Stiglitz, J. E., 1977. Monopolistic Competition and Optimum Product Diversity, American Economic Review 67, 297-308.

[9] Farmer, R. E. A., Guo, J., 1994. Real Business Cycles and the Animal Spirits Hypothesis, Journal of Economic Theory v63, 42-72.

[10] Fisher, J. D. M., 2002. Technology Shocks Matter, Federal Reserve Bank of Chicago, working paper.

[11] Fraumeni, B., 1997. The Measurement of Depreciation in the US National Income and Product Accounts, Survey of Current Business, 7-23.

[12] Gallant, A. R., 1987. Nonlinear Statistical Models (John Wiley \& Sons, New York).

[13] Gordon, R. J., 1990. The measurement of durable goods prices (University of Chicago Press, Chicago).

[14] Gort, M., Greenwood, J. and Rupert, P., 1999. Measuring the Rate of Technological Progress in Structures, Review of Economic Dynamics, v2, 207-30.

[15] Greenwood, J. Hercowitz, Z., Krusell, P., 1997. Long-Run Implications of Investment-Specific Technological Change, American Economic Review 87, 342-62.

[16] Greenwood, J., Jovanovic, B., 2001. Accounting for growth, in: Hulten, C. R., Dean, E. R. Harper, M. J., eds., New developments in productivity analysis, (University of Chicago Press, Chicago) 179-222. 
[17] Hall, R. E., 1990. Invariance Properties of Solow's Productivity Residual, in: Diamond, P., ed., Growth/Productivity/Unemployment: Essays to Celebrate Bob Solow's Birthday, (MIT Press, Cambridge, MA) 71-112.

[18] Hall, R. E., 2001. The Stock Market and Capital Accumulation, American Economic Review, 91, 1185-1202.

[19] Helpman, E. and Trajtenberg, M., 1998. A Time to Sow and a Time to Reap: Growth Based on General Purpose Technologies, in: Helpman, E., ed., General purpose technologies and economic growth, (MIT Press, Cambridge and London) 55-83.

[20] Howitt, P., 1998. Measurement, Obsolescence, and General Purpose Technologies, in: Helpman, E., ed., General purpose technologies and economic growth, (MIT Press, Cambridge and London) 219-51.

[21] Howitt, P., 1996. On some problems in measuring knowledge-based growth, in: P. Howitt, ed., Implications of Knowledge-Based Growth for Micro-Economic Policies, (University of Calgary Press, Calgary) 9-29.

[22] Hulten, C. R., 1992. Growth Accounting When Technical Change Is Embodied in Capital, American Economic Review 82, 964-80

[23] Jones, C. I., Williams, J. C., 2000. Too Much of a Good Thing? The Economics of Investment in R\&D, Journal of Economic Growth 5, 65-85.

[24] Jorgenson, D. and Stiroh, K., 1999. Information Technology and Growth, American Economic Review, 89, 109-115.

[25] Jovanovic, B. and Rousseau, P. L., 2002. Mergers as Reallocation, National Bureau of Economic Research Working Paper: 9279.

[26] Laitner, J. P., 2000. Social Security Reform and National Wealth, Scandinavian Journal of Economics, 102, 349-371.

[27] Laitner, J. P. and Stolyarov, D. L., 2002. Technological Change and the Stock Market, forthcoming, American Economic Review.

[28] Landes, D. S., 1969. The unbound Prometheus: technological change and industrial development in Western Europe from 1750 to the present (Cambridge University Press, Cambridge).

[29] Mansfield, E., Schwartz, M., Wagner, S., 1981. Imitation Costs and Patents: An Empirical Study, Economic Journal, 91, 907-18.

[30] Mokyr, J., 1990, The lever of riches: Technological creativity and economic progress, (Oxford University Press, Oxford, New York, Toronto and Melbourne).

[31] Mowrey, D. C., Rosenberg, N., 1998. Paths of Innovation (Cambridge University Press, Cambridge).

[32] McGrattan, E. R., Prescott, E. C., 2000. Is the Stock Market Overvalued?, Federal Reserve Bank of Minneapolis Quarterly Review v24, 20-40. 
[33] Norrbin, S. 1993. The Relationship Between Price and Marginal Cost in US. Industry: A Contradiction, Journal of Political Economy 101, 1149-1164.

[34] Pakes, A. and Schankerman, M., 1984. The Rate of Obsolescence of Patents, Research Gestation Lags and the Private Rate of Return to Research Resources, in: Griliches Z. ,ed., R\&D, Patents and Productivity, (University of Chicago Press, Chicago and London) 315-38.

[35] Perli, R., 1998. Indeterminacy, Home Production, and the Business Cycle: A Calibrated Analysis, Journal of Monetary Economics 41, 105-25.

[36] Rosenberg, N., 1982. Inside the black box : technology and economics (Cambridge University Press, Cambridge, New York).

[37] Rotemberg, J. J., Woodford, Michael. Oligopolistic Pricing and the Effects of Aggregate Demand on Economic Activity, Journal of Political Economy 100, 1153-1207.

[38] Scherer, F. M., 1990. Industrial market structure and economic performance, 3d ed., (Houghton Mifflin, Boston).

[39] Schmitt-Grohe, S., 1997. Comparing Four Models of Aggregate Fluctuations due to SelfFulfilling Expectations, Journal of Economic Theory 72, 96-147.

[40] Shepherd, W. G., The economics of industrial organization (Prentice-Hall, Englewood Cliffs, NJ).

[41] Solow, R. M., 1956. A Contribution to the Theory of Economic Growth, Quarterly Journal of Economics 70, 65-94.

[42] Solow, R. M., 1960. Investment and Technological progress, in: Arrow, K., Karlin, S., Suppes, P., eds., Mathematical Methods in the Social Sciences 1959, (Stanford University Press, Stanford, CA) 89-104. 


\section{Appendix 1: Data Sources}

This appendix presents the data for Section 3's calculations.

Right hand side of (R1). $\quad M_{T}$ is private, nonresidential net worth. Source: U.S. Flow of Funds http ://www.federalreserve.gov/releases/z1/Current/data.htm

The construction is table L.100, row 1; minus L.100, row 25; minus L.106, row 15, and L.105, row 18; plus L.105, row 7, and row 10; plus L.108, row 10; minus L.106, row 14, and L108, row 15; plus L.107, row 1; minus L.107, row 23.

Right hand side of (R2). All NIPA data comes from

$$
\text { http : ///www.bea.doc.gov/bea/dn/nipaweb/SelectedTables.asp }
$$

$G P D^{*}$ is nominal GDP (table 1.1, row 1); less housing services (table 2.2, row 14); divided by personal consumption chain price index (table 7.1, row 7).

Right hand side of (R3). $I^{K}$ is fixed nonresidential investment (table 1.1, row 8); plus change in private inventories (table 1.1, row 12); divided by personal consumption chain price index (table 7.1 , row 7$)$.

Right hand side of (R4). "Employee compensation" is NIPA table 1.14, row 2; "proprietor wages and salaries (WS)" is table 1.15, row $13 ; N I^{*}$ is national income, table 1.9 , row 17 , less housing services, table 2.2, row 14; "proprietor's income" is table 1.14, row 9 . Then

$$
L S^{*}=\frac{\text { employee compensation }- \text { proprietor } \mathrm{WS}}{N I^{*}-\text { proprietor's income }- \text { proprietor } \mathrm{WS}} \cdot \frac{N I^{*}}{G D P^{*}} .
$$

Right hand side of (R5). $\quad D P^{*}$ is NIPA consumption of nonresidential fixed capital (table 5.2, row 8), divided by personal consumption chain price index (table 7.1, row 7).

Right hand side of (R6). $\tau$ is the indirect business tax rate: NIPA table 1.9, row 13, divided by table 1.5 , row 6 .

$r^{*}$ is as follows. Let $d_{1}$ be Flow of Funds nonfarm, non-financial corporate total financial assets; less nonfarm, non-financial corporate total financial liabilities; divided by nonfarm, non-financial corporate market value equity. Setting

$$
\omega \equiv \frac{d_{1}}{1-d_{1}}
$$

$\omega$ is debt as a fraction of business financing. Then

$$
r^{*}=\omega \cdot \text { interest }+(1-\omega) \cdot \text { equity }+(1-\omega) \cdot \operatorname{corp} \text { tax }- \text { inflation },
$$

where "interest" is the 6 -month nominal interest rate on prime commercial paper, series 4 from

$$
\text { http : //www.econ.yale.edu/ }{ }^{\sim} \text { shiller/data/chapt26.html }
$$

"equity" is percent appreciation in average share price plus dividend divided by share price (series 1-2 from the same source); "corp tax" is the same dividend, times the NIPA corporate profits 
tax liability (table 1.14, row 23), divided by NIPA aggregate dividends (table 1.14, row 25); and, "inflation" is percent rate of inflation for the NIPA personal consumption chain price index (table 7.1, row 7).

Right hand side of (R7) $p_{t}^{e}$ is the ratio of the price index for private non-residential investment and the price index for personal consumption. The numerator of the ratio is calculated in Fisher (2002) using Gordon (1990) quality-adjusted price index for producer durable equipment prior to 1983 and BEA price index for structures. After 1983, no adjustment to the BEA price index for private non-residential investment is made. The denominator is the NIPA personal consumption chain price index (table 7.1 , row 7 ).

\section{Appendix 2: Proofs}

\section{Proof of Lemma 1:}

To simplify notation for the proof, let $m=m_{f j t}, l=l_{f j t}, y=y_{f j t}, \pi=\pi_{f j t}$, and $m r=m r_{f j t}$. Let $Y_{-}=Y_{j t}-y$. Let $Y=Y_{t}$. Let $P=P_{j t}$. Let $W=W_{t}$ and $R=R_{t}$.

Step 1. Verify the formula for marginal revenue.

From (S5),

$$
Y_{-}+y=Y \cdot P^{\frac{1}{\eta-1}}
$$

So, if $T R(y)$ is a firm's total revenue, then

$$
T R(y)=P \cdot y=[Y]^{1-\eta} \cdot\left(Y_{-}+y\right)^{\eta-1} \cdot y .
$$

Differentiating with respect to $y$,

$$
M R(y)=[Y]^{1-\eta} \cdot\left(\left[Y_{-}+y\right]^{\eta-1}+(\eta-1) \cdot\left[Y_{-}+y\right]^{\eta-2} \cdot y\right)=P \cdot\left(1+(\eta-1) \cdot \frac{y}{Y_{-}+y}\right)
$$

Step 2. Derive the total cost function, marginal cost function, profit function, and first-order conditions of profit maximization for firm $f$.

By definition,

$$
\begin{gathered}
T C(y)=\min _{m, l}(R \cdot m+W \cdot l) \\
\text { s.t. } y \leq Z \cdot[m]^{\alpha} \cdot[l]^{\nu} .
\end{gathered}
$$

Since the set described by (26) is convex, the first order conditions determine the cost function.

The Lagrangian for the cost minimization problem is

$$
\mathcal{L} \equiv R \cdot m+W \cdot l+\mu \cdot\left\{y-Z \cdot[m]^{\alpha} \cdot[l]^{\nu}\right\} .
$$

and the first order conditions for $m$ and $l$ read

$$
R=\alpha \mu \frac{y}{m}, W=\nu \mu \frac{y}{l}
$$

By the envelope theorem,

$$
T C^{\prime}(y)=M C(y) \equiv \frac{d \mathcal{L}}{d y}=\frac{\partial \mathcal{L}}{\partial y}=\mu
$$

Write the profit function as a function of only $y$ :

$$
\pi^{*}(y)=T R(y)-T C(y) .
$$


Differentiating,

$$
\frac{d}{d y} \pi^{*}(y)=0 \Longleftrightarrow m r(y)=\mu
$$

One can now see from (27) that if $y$ is a critical point for $\pi^{*}($.$) if and only if (4)-(5) hold.$

We can solve for $T C(y)$ explicitly using the first order conditions (27):

$$
T C(y)=(\alpha+\nu) \cdot \mu y=\gamma \mu y .
$$

Substituting (27) into (26) yields:

$$
\begin{gathered}
y=(\mu y)^{\gamma} Z\left(\frac{\alpha}{R}\right)^{\alpha}\left(\frac{\nu}{W}\right)^{\nu}, \\
\mu y=y^{\frac{1}{\gamma}} \cdot\left[Z\left(\frac{\alpha}{R}\right)^{\alpha}\left(\frac{\nu}{W}\right)^{\nu}\right]^{-\frac{1}{\gamma}}
\end{gathered}
$$

Letting

$$
\xi=\left[Z\left(\frac{\alpha}{R}\right)^{\alpha}\left(\frac{\nu}{W}\right)^{\nu}\right]^{-\frac{1}{\gamma}}
$$

we can write

$$
T C(y)=\gamma \cdot \mu y=\gamma \cdot \xi \cdot y^{\frac{1}{\gamma}} .
$$

We can now write the profit function explicitly:

$$
\pi^{*}(y)=T R(y)-T C(y)=[Y]^{1-\eta} \cdot\left(Y_{-}+y\right)^{\eta-1} \cdot y-\gamma \cdot \xi \cdot y^{\frac{1}{\gamma}} .
$$

Making a change of variables

$$
q=y^{\frac{1}{\gamma}}, y(q)=q^{\gamma}
$$

we have

$$
\pi^{*}(y(q))=\hat{\pi}(q)=[Y]^{1-\eta} \cdot\left(Y_{-}+q^{\gamma}\right)^{\eta-1} \cdot q^{\gamma}-\gamma \xi q .
$$

For future reference, differentiating (28) yields

$$
\begin{gathered}
\hat{\pi}^{\prime}(q)=-(1-\eta) \frac{[Y]^{1-\eta} \cdot\left(Y_{-}+q^{\gamma}\right)^{\eta-1}}{Y_{-}+q^{\gamma}} \cdot \gamma \cdot q^{\gamma-1} \cdot q^{\gamma}+[Y]^{1-\eta} \cdot\left(Y_{-}+q^{\gamma}\right)^{\eta-1} \gamma \cdot q^{\gamma-1}-\gamma \xi \\
=[Y]^{1-\eta} \cdot\left(Y_{-}+q^{\gamma}\right)^{\eta-1} \cdot \gamma \cdot q^{\gamma-1} \cdot\left(1-(1-\eta) \frac{q^{\gamma}}{Y_{-}+q^{\gamma}}\right)-\gamma \xi \\
=\gamma\left(\frac{\hat{\pi}(q)}{q}+\gamma \xi\right) \omega(q)-\gamma \xi
\end{gathered}
$$

where

$$
\omega(q)=\left(1-(1-\eta) \frac{q^{\gamma}}{Y_{-}+q^{\gamma}}\right)
$$

Note that

$$
\omega(0)=1, \omega^{\prime}(q)<0 \text { for all } q \geq 0
$$

Taking the second derivative,

$$
\hat{\pi}^{\prime \prime}(q)=\gamma\left(\frac{\hat{\pi}^{\prime}(q)}{q}-\frac{\hat{\pi}(q)}{q^{2}}\right) \omega(q)+\gamma\left(\frac{\hat{\pi}(q)}{q}+\gamma \xi\right) \omega^{\prime}(q) .
$$


Step 3. We show that when (4)-(5) hold, (S6) must hold as well. Assume (4)-(5) hold. From (S7), $\hat{\pi}(q)=0 ; \hat{\pi}(0)=0$; and, from step $2, \hat{\pi}^{\prime}(q)=0$.

Suppose that there exists $q_{0}$ with $0<q_{0}<q$ and $\hat{\pi}\left(q_{0}\right)>\hat{\pi}(q)$. Without loss of generality, one can assume $\hat{\pi}^{\prime}\left(q_{0}\right)=0$. But then using (29) and (30),

$$
0=\hat{\pi}^{\prime}\left(q_{0}\right)>\gamma^{2} \cdot \xi \cdot \omega\left(q_{0}\right)-\gamma \cdot \xi>\gamma^{2} \cdot \xi \cdot \omega(q)-\gamma \cdot \xi=\hat{\pi}^{\prime}(q)=0 .
$$

This is impossible - contradicting the supposition of the existence of $q_{0}$.

Next, suppose there exists $q_{1}$ with $q_{1}>q$ and $\hat{\pi}\left(q_{1}\right)>\hat{\pi}(q)$. At $q$, (31) and (30) imply

$$
\hat{\pi}^{\prime \prime}(q)=\gamma^{2} \cdot \xi \cdot \omega^{\prime}(q)<0 .
$$

Hence, $q$ is a local maximum for $\hat{\pi}($.$) . If the global maximum is to the right of q$, there exists $q_{2}$ with $q<q_{2}<q_{1}$ and $\hat{\pi}\left(q_{2}\right)=0$ and $\hat{\pi}^{\prime}\left(q_{2}\right) \geq 0$. But then

$$
0 \leq \hat{\pi}^{\prime}\left(q_{2}\right)=\gamma^{2} \cdot \xi \cdot \omega\left(q_{2}\right)-\gamma \cdot \xi<\gamma^{2} \cdot \xi \cdot \omega(q)-\gamma \cdot \xi=\hat{\pi}^{\prime}(q)=0 .
$$

This is impossible — contradicting the supposition of the existence of $q_{1}$.

Hence $q$ is the global maximum of $\hat{\pi}($.$) .$

Step 4. Suppose all conditions for equilibrium hold. Then each firm must be maximizing profit. Hence, steps 1-2 show (4)-(5) must hold.

\section{Proof of Proposition 1:}

Laitner and Stolyarov [2002] cover the case with $\gamma=1$. Assume $\gamma>1$.

Step 1. We prove that any equilibrium satisfying profit maximization condition (S6) and zero profit condition (S7) must be symmetric. That is,

$$
N_{j t}=N_{t}, \quad P_{j t}=P_{t}, \quad y_{f j t}=y_{t}, \quad Y_{j t}=Y_{t}, \quad m_{f j t}=m_{t}, \quad l_{f j t}=l_{t} .
$$

Let $Y_{t}, W_{t}$ and $R_{t}$ be the equilibrium aggregate output, rental fee on capital and wage, respectively. Fix $Y_{t}=Y, W_{t}$ and $R_{t}$. Using the notation of Lemma 1, define a firm's indirect profit function

$$
\Pi\left(Y_{-}\right)=\max _{y}\left\{Y^{1-\eta} \cdot\left(Y_{-}+y\right)^{\eta-1} \cdot y-\gamma \cdot \xi \cdot y^{\frac{1}{\gamma}}\right\}
$$

It is immediate that $\Pi\left(Y_{-}\right)$is continuous and strictly decreasing in $Y_{-}$. Then, if there exists a $Y_{-}^{*}$ such that $\Pi\left(Y_{-}^{*}\right)=0$, it is unique. Let

$$
y^{*}=\arg \max _{y}\left\{Y^{1-\eta} \cdot\left(Y_{-}^{*}+y\right)^{\eta-1} \cdot y-\gamma \cdot \xi \cdot y^{\frac{1}{\gamma}}\right\}
$$

Lemma 1, step 3, establishes that $y^{*}$ is unique. Then for any $Y_{t}, W_{t}$ and $R_{t}$, there is a unique corresponding industry output level, $Y_{-}^{*}+y^{*}$, such that (S6) and (S7) are satisfied. The above expression also implies that each firm must produce the same output $y^{*}$. Then from (29),

$$
\begin{gathered}
\frac{Y_{-}^{*}+y^{*}}{y^{*}}=N_{j}=\frac{\gamma}{\gamma-1} \cdot(1-\eta) \text { all } j \\
Y_{j}=\frac{\gamma}{\gamma-1} \cdot(1-\eta) y^{*}
\end{gathered}
$$


From (S3), $Y_{t}=Y_{j t}=Y_{j}$, and from $(\mathrm{S} 5), P_{j t}=P_{t}=1$. Finally, Lemma 1 implies that

$$
m_{f j t}=m_{t} \text { and } l_{f j t}=l_{t}, \text { all } f, j, t .
$$

We now prove existence and uniqueness of a symmetric equilibrium.

Step 2. Existence.

Set $N$ with

$$
N=\frac{\gamma}{\gamma-1} \cdot(1-\eta) \Longleftrightarrow \gamma \cdot\left(1-\frac{1-\eta}{N}\right)=1
$$

Solve differential equation (7) for $M_{t}$ all $t \geq 0$. Set $m_{f j t} \equiv m_{t}=M_{t} / N$. Then (S2) holds. Set $l_{f j t} \equiv l_{t}=L_{t} / N$. Then (S8) holds. Set $P_{j t}=P_{t}=1$ all $t$. Then (S4) holds. Set

$$
y_{f j t} \equiv y_{t}=Z \cdot\left[m_{t}\right]^{\alpha} \cdot\left[l_{t}\right]^{\nu} .
$$

Then (S1) holds. Set $Y_{j t}=Y_{t}=N \cdot y_{t}$. Then (S3) and (S5) hold.

Using Lemma 1 and (32),

$$
m r_{f j t}=m r_{t}=1-(1-\eta) \cdot \frac{y_{t}}{Y_{t}}=1-\frac{1-\eta}{N}=\frac{1}{\gamma} .
$$

Set $W_{t}$ and $R_{t}$ from (4)-(5). Then

$$
\pi_{f j t}=y_{t}-\alpha \cdot m r_{t} \cdot y_{t}-\nu \cdot m r_{t} \cdot y_{t}=y_{t} \cdot\left(1-\gamma \cdot m r_{t}\right) .
$$

From (33), $\pi_{f j t}=0$. So, (S7) holds. Lemma 1 and the construction of $W$ and $R$ then imply (S6). From (7),

$$
\dot{M}_{t}+\delta M_{t}=\sigma Z N\left(\frac{M_{t}}{N}\right)^{\alpha}\left(\frac{L_{t}}{N}\right)^{\nu}=\sigma \cdot y_{t} \cdot N=\sigma \cdot Y_{t} .
$$

Then (S9) holds. That establishes existence.

Step 3. Uniqueness.

Suppose we have a symmetric equilibrium. Show that in any symmetric equilibrium $N_{t}$ is constant. With symmetry, (S4) implies $P_{j t}=1$ all $j, t$; (S3) implies $Y_{t}=N_{t} \cdot y_{t}$; and, the formula from Proposition 1 implies

$$
m r_{f j t}=m r_{t}=1-\frac{1-\eta}{N_{t}}
$$

Lemma 1 shows (4)-(5) hold; thus,

$$
\pi_{f j t}=\pi_{t}=y_{t}-\alpha \cdot m r_{t} \cdot y_{t}-\nu \cdot m r_{t} \cdot y_{t}=y_{t} \cdot\left[1-\gamma \cdot m r_{t}\right]
$$

Then from (S7),

$$
1=\gamma \cdot m r_{t}
$$

So, as in step 2,

$$
m r_{t}=\frac{1}{\gamma} \text { and } N_{t}=N \equiv \frac{\gamma}{\gamma-1} \cdot(1-\eta)
$$

Next, show that in any symmetric equilibrium with constant $N, M_{t}$ solves (7). 
From (S9),

$$
\dot{M}_{t}+\delta M_{t}=\sigma \cdot Y_{t}=\sigma \cdot y_{t} \cdot N=\sigma Z N\left(\frac{M_{t}}{N}\right)^{\alpha}\left(\frac{L_{t}}{N}\right)^{\nu}=\sigma \bar{Z} M_{t}^{\alpha} L_{t}^{\nu}
$$

Thus, (7) must hold. Hence, we are back to the same equilibrium as step 2 - which establishes uniqueness.

Proof of Corollary to Proposition 1:

From the definition of a SSE, $g_{R}=0$. Proposition 1 shows that $g_{N}=0$ and $g_{m r}=0$, and (3) implies that $g_{l}=n$.

First order conditions (4) and (5) then imply $g_{y}=g_{m}$ and $g_{W}=g_{y}-n$. Then (S1) shows

$$
g_{y}=\frac{\nu \cdot n}{1-\alpha} \text {. }
$$

Since $N$ is constant,

$$
g_{Y}=g_{y}=g_{m} .
$$

Finally,

$$
g_{W}=g_{y}-n=\frac{\gamma-1}{1-\alpha} n .
$$

\section{Proof of Lemma 2:}

(i) Take any two vintages of capital, $i$ and $i^{\prime}$. A rental company that owns one physical unit of capital of vintage $i$ and rents it to firm $f$ in industry $j$ receives the same rental payment as a company that owns $m^{i^{\prime}}=\left(Z_{i} / Z_{i^{\prime}}\right)^{\frac{1}{\alpha}}$ units of capital of vintage $i^{\prime}$ and rents it to the same firm:

$$
P_{j t} Z_{i}\left(l_{f j t}^{i}\right)^{\nu}-W_{t} \cdot l_{f j t}^{i}=P_{j t} Z_{i^{\prime}}\left(m^{i^{\prime}}\right)^{\alpha}\left(l_{f j t}^{i}\right)^{\nu}-W_{t} \cdot l_{f j t}^{i} \text { all } i, i^{\prime} .
$$

Since capital of every vintage depreciates at the same rate, the above equality holds for all $t$. That is, for any $i$ and $i^{\prime}$ holding one unit of capital vintage $i$ and $\left(Z_{i} / Z_{i^{\prime}}\right)^{\frac{1}{\alpha}}$ units of capital vintage $i^{\prime}$ generates identical sequences of rental payments. Free entry in the rental sector implies that two assets with the same stream of rental payments must sell for the same price:

$$
\frac{P_{i t}^{M}}{P_{i^{\prime} t}^{M}}=\left(\frac{Z_{i}}{Z_{i^{\prime}}}\right)^{\frac{1}{\alpha}} \text { all } i, i^{\prime}, t \geq \max \left\{t_{i}, t_{i^{\prime}}\right\}
$$

(ii) From the zero profit condition for the firms, the left hand side of (34) equals $R_{i t} P_{i t}^{M}$, and the right hand side equals $R_{i^{\prime} t} P_{i^{\prime} t}^{M} \cdot m^{i^{\prime}}$. Then

$$
\frac{R_{i t}}{R_{i^{\prime} t}}=\frac{P_{i^{\prime} t}^{M}}{P_{i t}^{M}}\left(\frac{Z_{i}}{Z_{i^{\prime}}}\right)^{\frac{1}{\alpha}}=1 .
$$

(iii) Since $P_{\iota(t), t}^{M}=1, P_{i t}^{M}<1$ for all $i<\iota(t)$. Then investment in vintages other than $\iota(t)$ generates an immediate capital loss. Therefore, all new investment at time $t$ must be in the latest vintage $\iota(t)$. 
(iv) Take an arbitrary firm $f$ in industry $j$ at time $t$ (the $f, j$, and $t$ subscripts will be dropped for convenience). A firm chooses $y$ and $\left\{m_{i}, l_{i}\right\}_{i=0}^{\iota}$ to solve

$$
\max _{y} \pi(y)=\max _{y}(P(y) \cdot y-T C(y))
$$

where $P(y)$ is the industry demand curve given by (S5) and $T C(y)$ is the total cost function:

$$
\begin{gathered}
T C(y)=\min _{\left\{m_{i}, l_{i}\right\}_{i=0}^{\iota}} \sum_{i=0}^{\iota}\left(R P_{i}^{M} m_{i}+W l_{i}\right) \\
\text { s.t. } \quad \sum_{i=0}^{\iota(t)} Z_{i}\left[m_{i t}\right]^{\alpha}\left[l_{i t}\right]^{\nu} \geq y .
\end{gathered}
$$

We first demonstrate that for any positive factor prices, the solution to the cost minimization problem (36)-(37) involves the firm using just one technology. Suppose, to the contrary, that we have a candidate optimum where the firm uses more than one technology. Formally let $J \subseteq\{0, \ldots, \iota(t)\}$ be the subset of available technologies used by the firm such that $|J|>1$ and

$$
l_{i}>0 \Longleftrightarrow i \in J
$$

For any $i \in J$, the first order conditions for $m_{i}$ and $l_{i}$ hold as equalities. This implies that

$$
m_{i}=\frac{\alpha}{\nu} \frac{W}{R P_{i}^{M}} l_{i}
$$

and that output produced with technology $i \in J$ must equal

$$
y_{i}=Z_{i} m_{i}^{\alpha} l_{i}^{\nu}=Z_{i}\left(\frac{\alpha}{\nu} \frac{W}{R P_{i}^{M}}\right)^{\alpha} l_{i}^{\gamma} .
$$

Let

$$
\zeta_{i}=Z_{i}\left(\frac{\alpha}{\nu} \frac{W}{R P_{i}^{M}}\right)^{\alpha} .
$$

Then, substituting (38) into (36) and (37) and noting that $l_{i}=0$ for any $i \notin J$, we find that $\left\{l_{i}\right\}_{i \in J}$ must solve

$$
\begin{gathered}
\min \left(\frac{\alpha}{\nu}+1\right) W \sum_{i \in J} l_{i} \\
\text { s.t. } \sum_{i \in J} \zeta_{i} l_{i}^{\gamma} \geq y .
\end{gathered}
$$

However, because $\gamma \geq 1$, this problem always has only corner solutions, which contradicts our supposition that $|J|>1$. Therefore, a necessary condition for cost minimization is that every firm produces all its output with just one technology.

(v) In equilibrium, any technology gives the firm the same cost function, because

$$
P_{i}^{M}=\left(\frac{Z_{i}}{Z_{\iota}}\right)^{\frac{1}{\alpha}} \Leftrightarrow \zeta_{i}=\zeta_{\iota} .
$$

We can now repeat step 1 of Proposition 1 to prove that $y_{f j t}=y_{t}$. Then (39) shows each firm employs the same amount of labor, $l_{f j t}^{i}=l_{t}$. 


\section{Proof of Proposition 2:}

Step 1. Existence. Set

$$
N_{t}=N=\frac{\gamma}{\gamma-1}(1-\eta)
$$

Take any increasing sequence $\left\{Z_{i}, t_{i}\right\}_{i=0}^{\iota(t)}$. Solve (14) on each $\left(t_{i-1}, t_{i}\right)$, using $M_{t_{0}}=M_{0,0}$ and the terminal value $M_{t i}$ from one interval as the initial condition for $M_{t}$ on $\left(t_{i}, t_{i+1}\right)$. Use (11) to compute $Y_{t}$ from $M_{t}$ and $L_{t}$. Construct $M_{i t}$ for every $i$ using (9). Set $P_{i t}^{M}$ according to (8); set $R_{i t}=R_{t}$ and $W_{t}$ from (12); and, set $\varphi\left(Z_{i}, t\right)$ from (10).

At each $t$,divide $[0,1]$ into disjoint intervals $F_{i t}$ such that

$$
\bigcup_{i=0}^{\iota(t)} F_{i t}=[0,1], \int_{F_{i t}} d j=\varphi\left(Z_{i}, t\right) .
$$

In other words, industry $j \in F_{i t}$ uses only capital of vintage $i$. Set

$$
l_{f j t}^{i}=\left\{\begin{array}{ll}
\frac{L_{t}}{N}, & f \in F_{i t} \\
0, & \text { otherwise }
\end{array} .\right.
$$

Then $\sum_{i=0}^{\iota(t)} l_{f j t}^{i}=\frac{L_{t}}{N}$, and the labor market clearing (E9) is satisfied:

$$
\int_{0}^{1} \sum_{f=1}^{N} \sum_{i=0}^{\iota(t)} l_{f j t}^{i} d j=\int_{0}^{1} \sum_{f=1}^{N} \frac{L_{t}}{N} d j=L_{t} .
$$

Differentiating (9), $M_{i t}$ satisfies (E11) and $I_{i t}=\dot{M}_{i t}+\delta M_{i t}$ satisfies (E12). (E4) holds by construction. From (9),

$$
I_{i t}=\left\{\begin{array}{ll}
\sigma Y_{t}, & i=\iota(t) \\
0, & \text { otherwise }
\end{array} .\right.
$$

Then market clearing condition (E10) holds.

Set

$$
m_{f j t}^{i}=\left\{\begin{array}{ll}
\frac{M_{t}}{P_{i t}^{M} N}, & f \in F_{i t} \\
0, & \text { otherwise }
\end{array} .\right.
$$

Then (E2) holds:

$$
\int_{0}^{1} \sum_{f=1}^{N} m_{f j t}^{i} d j=\int_{F_{i t}} \sum_{f=1}^{N} \frac{M_{t}}{P_{i t}^{M} N} d j=\frac{M_{t}}{P_{i t}^{M}} \int_{F_{i t}} d j=\frac{M_{t}}{P_{i t}^{M}} \varphi\left(Z_{i}, t\right)=M_{i t}, \text { all } i .
$$

Given $j$ and $t, j \in F_{i t}$ for one and only one $i$. Fix this $i$, and set $y_{f j t}$ from (E1), with the latter then holding by construction. Industry output can be expressed as

$$
Y_{j t}=\sum_{f=1}^{N} y_{f j t}=\sum_{f=1}^{N} Z_{i}\left(\frac{M_{t}}{N P_{i t}^{M}}\right)^{\alpha}\left(\frac{L_{t}}{N}\right)^{\nu}=\frac{Z_{\iota}}{N^{\gamma-1}} M_{t}^{\alpha} L_{t}^{\nu}=Y_{t}
$$

Then (E3) holds. Conditions (E5) and (E6) hold by construction. 
Condition (E8) holds: for any $j$ and $i$ such that $j \in F_{i t}$, using $R_{t}$ and $W_{t}$ from (12),

$$
\begin{gathered}
\pi_{f j t}=P_{j t} \cdot y_{f j t}-R_{t} \cdot P_{i t}^{M} \cdot m_{f j t}^{i}-W_{t} \cdot l_{f j t}^{i}= \\
=\frac{Y_{t}}{N}-\frac{\alpha}{\gamma} \frac{Y_{t}}{N}-\frac{\nu}{\gamma} \frac{Y_{t}}{N}=0 .
\end{gathered}
$$

Using (11) and (12),

$$
\begin{gathered}
\frac{\alpha}{\gamma} \frac{y_{t}}{m_{f j t}^{i}}=\frac{\alpha}{\gamma} \frac{\frac{Z_{\iota(t)}}{N^{\gamma}} M_{t}^{\alpha} L_{t}^{\nu}}{M_{t} / N}=\frac{\alpha}{\gamma} \frac{Y_{t}}{M_{t}}=R_{t}, \\
\frac{\nu}{\gamma} \frac{y_{t}}{l_{f j t}^{i}}=\frac{\nu}{\gamma} \frac{\frac{Z_{\iota(t)}}{N^{\gamma}} M_{t}^{\alpha} L_{t}^{\nu}}{L_{t} / N}=\frac{\nu}{\gamma} \frac{Y_{t}}{L_{t}}=W_{t} .
\end{gathered}
$$

Therefore, conditions (4), (5) hold for every firm. Profit maximization (E7) then also holds by Lemma 1.

Step 2. Show any equilibrium has the same $P_{i t}^{M}, M_{i t}, N_{t}, \varphi(\cdot), Y_{t}, M_{t}, R_{i t}, R_{t}$ and $W_{t}$. Consider any equilibrium.

Lemma 2, part (i), shows $P_{i t}^{M}$ is the same any equilibrium.

Lemma 2 shows that in equilibrium every firm has an identical cost function; hence, step 1 of Proposition 1 shows that all industries must be symmetric. That is

$$
N_{j t}=N_{t}, \quad \text { and } \quad Y_{j t}=Y_{t} \text { all } j, t .
$$

According to Lemma $2, y_{f j t}=y_{t}$, so $Y_{t}=y_{t} \cdot N_{t}$. Repeating step 3 of Proposition 1 , any equilibrium must have the number of firms equal to

$$
N_{t}=N=\frac{\gamma}{\gamma-1}(1-\eta)
$$

Using symmetry in (E6), we immediately see that $P_{j t}=1$, all $j, t$. And, Lemma 2, part (v) shows that $l_{f j t}=\frac{L_{t}}{N}$.

We show that the aggregate production function (11) holds in any equilibrium. Let $\chi_{f j t}(i)=1$ if firm $f j t$ uses capital of vintage $i$ and let $\chi_{f j t}(i)=0$ otherwise. The proof of Lemma 2 shows that if firm $f j t$ uses $i, P_{i t}^{M} \cdot m_{f j t}^{i}$ is a number independent of $i, j$ and $f$. Call this number $m_{t}$. Then

$$
\begin{aligned}
M_{t} & =\sum_{i=0}^{\iota(t)} P_{i t}^{M} M_{i t}=\sum_{i=0}^{\iota(t)} \int_{0}^{1} \sum_{f=1}^{N} \chi_{f j t}(i) \cdot P_{i t}^{M} \cdot m_{f j t}^{i} d j=m_{t} \sum_{i=0}^{\iota(t)} \int_{0}^{1} \sum_{f=1}^{N} \chi_{f j t}(i) d j= \\
& =m_{t} \int_{0}^{1} \sum_{f=1}^{N} \sum_{i=0}^{\iota(t)} \chi_{f j t}(i) d j=m_{t} \int_{0}^{1} \sum_{f=1}^{N} 1 d j=m_{t} \cdot N .
\end{aligned}
$$

Consider a firm that uses capital of vintage $\iota(t)$. We have seen that this firm employs $\frac{L_{t}}{N}$ units of labor and $m_{t}$ units of capital. Then its output is

$$
y_{t}=Z_{\iota(t)} \cdot m_{t}^{\alpha}\left(\frac{L_{t}}{N}\right)^{\nu}=\frac{Z_{\iota(t)}}{N^{\gamma}} M_{t}^{\alpha} L_{t}^{\nu},
$$

and, by symmetry,

$$
Y_{t}=y_{t} N=\frac{Z_{\iota(t)}}{N^{\gamma-1}} M_{t}^{\alpha} L_{t}^{\nu} \text { all } t
$$


We show that $M_{t}$ must be the same in any equilibrium. (E10) and (E12) imply that (9) must hold. Differentiating (9) for every $i$, we have

$$
\sum_{i=0}^{\iota(t)} P_{i t}^{M} \dot{M}_{i t}=\sigma Y_{t}-\delta \cdot \sum_{i=0}^{\iota(t)} P_{i t}^{M} M_{i t},
$$

which is the same expression as (14), given our aggregate production function (11). Thus, every equilibrium has the same $M_{t}$ and $Y_{t}$.

It follows from symmetry that every equilibrium has the same $y_{f j t}$ and $Y_{j t}$. Equation (9) shows that $M_{i t}$ is the same as well. Lemma 2 shows that $R_{i t}=R_{t}$. Lemma 1 shows that(12) must hold; therefore, $R_{t}$ and $W_{t}$ are always the same.

Finally,

$$
\begin{aligned}
\varphi\left(Z_{i}, t\right) & =\frac{1}{N} \int_{0}^{1} \sum_{f=1}^{N} \chi_{f j t}(i) d j=\frac{m_{t}}{M_{t}} \int_{0}^{1} \sum_{f=1}^{N} \chi_{f j t}(i) d j= \\
& =\frac{P_{i t}^{M}}{M_{t}} \int_{0}^{1} \sum_{f=1}^{N} \chi_{f j t}(i) \cdot m_{f j t}^{i} d j=\frac{P_{i t}^{M}}{M_{t}} M_{i t} .
\end{aligned}
$$


Table 1. Estimation results

\begin{tabular}{|c|c|c|c|c|c|c|}
\hline \multicolumn{7}{|c|}{ Flow model: Point estimates (Standard errors in parenthesis) } \\
\hline & \multicolumn{3}{|c|}{ Labor Series 1} & \multicolumn{3}{|c|}{ Labor series 2} \\
\hline Revolution date & 1972 & 1973 & 1974 & 1972 & 1973 & 1974 \\
\hline $\begin{array}{l}\text { Share of intangible } \\
\text { capital, } \alpha_{A}\end{array}$ & $\begin{array}{c}0.077 \\
(0.059) \\
\end{array}$ & $\begin{array}{c}0.077 \\
(0.059) \\
\end{array}$ & $\begin{array}{c}0.112 \\
(0.044)\end{array}$ & $\begin{array}{c}0.077 \\
(0.050)\end{array}$ & $\begin{array}{c}0.032 \\
(0.066)\end{array}$ & $\begin{array}{c}0.078 \\
(0.047) \\
\end{array}$ \\
\hline $\begin{array}{l}\text { Share of physical } \\
\text { capital, } \alpha_{K}\end{array}$ & $\begin{array}{c}0.282 \\
(0.043) \\
\end{array}$ & $\begin{array}{c}0.255 \\
(0.043) \\
\end{array}$ & $\begin{array}{c}0.222 \\
(0.032) \\
\end{array}$ & $\begin{array}{c}0.215 \\
(0.034) \\
\end{array}$ & $\begin{array}{c}0.245 \\
(0.046) \\
\end{array}$ & $\begin{array}{c}0.210 \\
(0.031) \\
\end{array}$ \\
\hline Returns to scale, $\gamma$ & $\begin{array}{c}1.34 \\
(0.067)\end{array}$ & $\begin{array}{c}1.29 \\
(0.075)\end{array}$ & $\begin{array}{c}1.15 \\
(0.067)\end{array}$ & $\begin{array}{c}1.06 \\
(0.053)\end{array}$ & $\begin{array}{c}1.09 \\
(0.055)\end{array}$ & $\begin{array}{c}1.04 \\
(0.051)\end{array}$ \\
\hline $\begin{array}{l}\text { Physical } \\
\text { depreciation rate, } \delta\end{array}$ & $\begin{array}{c}0.053 \\
(0.013) \\
\end{array}$ & $\begin{array}{c}0.047 \\
(0.014) \\
\end{array}$ & $\begin{array}{c}0.056 \\
(0.014) \\
\end{array}$ & $\begin{array}{c}0.046 \\
(0.015) \\
\end{array}$ & $\begin{array}{c}0.034 \\
(0.016) \\
\end{array}$ & $\begin{array}{c}0.047 \\
(0.015) \\
\end{array}$ \\
\hline Savings rate, $\sigma$ & $\begin{array}{c}0.150 \\
(0.025) \\
\end{array}$ & $\begin{array}{c}0.154 \\
(0.028) \\
\end{array}$ & $\begin{array}{c}0.173 \\
(0.025) \\
\end{array}$ & $\begin{array}{c}0.159 \\
(0.028) \\
\end{array}$ & $\begin{array}{c}0.136 \\
(0.030) \\
\end{array}$ & $\begin{array}{c}0.161 \\
(0.027) \\
\end{array}$ \\
\hline Growth rate, $g_{0}$ & $\begin{array}{c}0.0057 \\
(0.0012) \\
\end{array}$ & $\begin{array}{c}0.0080 \\
(0.0012) \\
\end{array}$ & $\begin{array}{c}0.0093 \\
(0.0011) \\
\end{array}$ & $\begin{array}{c}0.0065 \\
(0.0012) \\
\end{array}$ & $\begin{array}{c}0.0061 \\
(0.0011) \\
\end{array}$ & $\begin{array}{c}0.0074 \\
(0.0011) \\
\end{array}$ \\
\hline Growth rate, $g_{1}$ & $\begin{array}{c}0.0035 \\
(0.0012) \\
\end{array}$ & $\begin{array}{c}0.0057 \\
(0.0013) \\
\end{array}$ & $\begin{array}{c}0.0059 \\
(0.0014) \\
\end{array}$ & $\begin{array}{c}0.0060 \\
(0.0011) \\
\end{array}$ & $\begin{array}{c}0.0059 \\
(0.0012) \\
\end{array}$ & $\begin{array}{c}0.0059 \\
(0.0014) \\
\end{array}$ \\
\hline TFP level $Z_{0}$ & $\begin{array}{l}20.15 \\
(2.41) \\
\end{array}$ & $\begin{array}{l}17.18 \\
(2.36) \\
\end{array}$ & $\begin{array}{l}14.92 \\
(2.07) \\
\end{array}$ & $\begin{array}{l}13.67 \\
(1.44) \\
\end{array}$ & $\begin{array}{c}14.71 \\
(1.09) \\
\end{array}$ & $\begin{array}{l}13.49 \\
(1.39) \\
\end{array}$ \\
\hline \multicolumn{7}{|c|}{ Calculated parameters } \\
\hline $\begin{array}{l}\text { Capital share, } \alpha \\
\text { (95\% confidence } \\
\text { interval) }\end{array}$ & $\begin{array}{c}0.36 \\
(0.32,0.40)\end{array}$ & $\begin{array}{c}0.33 \\
(0.29,0.37)\end{array}$ & $\begin{array}{c}0.33 \\
(0.30,0.37)\end{array}$ & $\begin{array}{c}0.29 \\
(0.26,0.33)\end{array}$ & $\begin{array}{c}0.28 \\
(0.23,0.32)\end{array}$ & $\begin{array}{c}0.29 \\
(0.25,0.32)\end{array}$ \\
\hline $\begin{array}{l}\text { Share of intangible } \\
\text { capital in } M, \theta\end{array}$ & 0.21 & 0.23 & 0.34 & 0.26 & 0.12 & 0.27 \\
\hline $\begin{array}{l}\text { Test of } \\
\text { overidentifying } \\
\text { restrictions, p- } \\
\text { value, } \chi^{2}(S(\cdot), 15)\end{array}$ & 0.871 & 0.851 & 0.876 & 0.884 & 0.854 & 0.883 \\
\hline \multicolumn{7}{|c|}{ Punctuated model: Point estimates (Standard errors in parenthesis) } \\
\hline & \multicolumn{3}{|c|}{ Labor Series 1} & \multicolumn{3}{|c|}{ Labor series 2} \\
\hline Revolution date & 1972 & 1973 & 1974 & 1972 & 1973 & 1974 \\
\hline $\begin{array}{l}\text { Share of intangible } \\
\text { capital, } \alpha_{A}\end{array}$ & $\begin{array}{c}0.130 \\
(0.052) \\
\end{array}$ & $\begin{array}{c}0.113 \\
(0.055) \\
\end{array}$ & $\begin{array}{c}0.114 \\
(0.051) \\
\end{array}$ & $\begin{array}{c}0.057 \\
(0.061) \\
\end{array}$ & $\begin{array}{c}0.028 \\
(0.066) \\
\end{array}$ & $\begin{array}{c}0.064 \\
(0.056) \\
\end{array}$ \\
\hline $\begin{array}{l}\text { Share of physical } \\
\text { capital, } \alpha_{K}\end{array}$ & $\begin{array}{c}0.229 \\
(0.032)\end{array}$ & $\begin{array}{c}0.250 \\
(0.036)\end{array}$ & $\begin{array}{c}0.248 \\
(0.034)\end{array}$ & $\begin{array}{c}0.233 \\
(0.039)\end{array}$ & $\begin{array}{c}0.253 \\
(0.046)\end{array}$ & $\begin{array}{c}0.235 \\
(0.036)\end{array}$ \\
\hline Returns to scale, $\gamma$ & $\begin{array}{c}1.22 \\
(0.059)\end{array}$ & $\begin{array}{c}1.29 \\
(0.063)\end{array}$ & $\begin{array}{c}1.27 \\
(0.058)\end{array}$ & $\begin{array}{c}1.09 \\
(0.044)\end{array}$ & $\begin{array}{c}1.11 \\
(0.044)\end{array}$ & $\begin{array}{c}1.11 \\
(0.041)\end{array}$ \\
\hline $\begin{array}{l}\text { Physical } \\
\text { depreciation rate, } \delta\end{array}$ & $\begin{array}{c}0.066 \\
(0.016) \\
\end{array}$ & $\begin{array}{c}0.061 \\
(0.014) \\
\end{array}$ & $\begin{array}{c}0.061 \\
(0.014) \\
\end{array}$ & $\begin{array}{c}0.049 \\
(0.016) \\
\end{array}$ & $\begin{array}{c}0.041 \\
(0.015) \\
\end{array}$ & $\begin{array}{c}0.050 \\
(0.014) \\
\end{array}$ \\
\hline Savings rate, $\sigma$ & $\begin{array}{c}0.179 \\
(0.028) \\
\end{array}$ & $\begin{array}{c}0.169 \\
(0.027) \\
\end{array}$ & $\begin{array}{c}0.171 \\
(0.025) \\
\end{array}$ & $\begin{array}{c}0.148 \\
(0.030) \\
\end{array}$ & $\begin{array}{c}0.135 \\
(0.030) \\
\end{array}$ & $\begin{array}{c}0.151 \\
(0.028) \\
\end{array}$ \\
\hline TFP level $Z_{0}$ & $\begin{array}{l}17.04 \\
(2.19) \\
\end{array}$ & $\begin{array}{l}20.39 \\
(2.69) \\
\end{array}$ & $\begin{array}{l}19.25 \\
(2.29) \\
\end{array}$ & $\begin{array}{l}14.87 \\
(1.01) \\
\end{array}$ & $\begin{array}{l}15.78 \\
(0.81)\end{array}$ & $\begin{array}{l}15.88 \\
(1.07)\end{array}$ \\
\hline
\end{tabular}




\begin{tabular}{|c|c|c|c|c|c|c|}
\hline $\begin{array}{l}\text { TFP change, } \\
Z_{1}-Z_{0}\end{array}$ & $\begin{array}{c}3.28 \\
(0.33)\end{array}$ & $\begin{array}{c}3.29 \\
(0.33)\end{array}$ & $\begin{array}{c}3.41 \\
(0.26)\end{array}$ & $\begin{array}{c}2.62 \\
(0.23)\end{array}$ & $\begin{array}{c}2.67 \\
(0.28)\end{array}$ & $\begin{array}{c}2.69 \\
(0.17)\end{array}$ \\
\hline \multicolumn{7}{|c|}{ Calculated parameters } \\
\hline $\begin{array}{l}\text { Capital share, } \alpha \\
\text { ( } 95 \% \text { confidence } \\
\text { interval) }\end{array}$ & $\begin{array}{c}0.36 \\
(0.32,0.40)\end{array}$ & $\begin{array}{c}0.36 \\
(0.32,0.41)\end{array}$ & $\begin{array}{c}0.36 \\
(0.32,0.41)\end{array}$ & $\begin{array}{c}0.29 \\
(0.24,0.34)\end{array}$ & $\begin{array}{c}0.28 \\
(0.23,0.33)\end{array}$ & $\begin{array}{c}0.30 \\
(0.26,0.34)\end{array}$ \\
\hline $\begin{array}{l}\text { Share of intangible } \\
\text { capital in } M, \theta\end{array}$ & 0.36 & 0.31 & 0.32 & 0.20 & 0.10 & 0.21 \\
\hline $\begin{array}{l}\text { Test of } \\
\text { overidentifying } \\
\text { restrictions, p- } \\
\text { value, } \chi^{2}(S(\cdot), 14)\end{array}$ & 0.870 & 0.862 & 0.828 & 0.818 & 0.762 & 0.743 \\
\hline \multicolumn{7}{|c|}{ Combined model: Point estimates (Standard errors in parenthesis) } \\
\hline & \multicolumn{3}{|c|}{ Labor Series 1} & \multicolumn{3}{|c|}{ Labor series 2} \\
\hline Revolution date & 1972 & 1973 & 1974 & 1972 & 1973 & 1974 \\
\hline $\begin{array}{l}\text { Share of intangible } \\
\text { capital, } \alpha_{A}\end{array}$ & $\begin{array}{c}0.107 \\
(0.050) \\
\end{array}$ & $\begin{array}{c}0.086 \\
(0.046) \\
\end{array}$ & $\begin{array}{c}0.121 \\
(0.043) \\
\end{array}$ & $\begin{array}{c}0.071 \\
(0.053) \\
\end{array}$ & $\begin{array}{c}0.042 \\
(0.054) \\
\end{array}$ & $\begin{array}{c}0.085 \\
(0.030) \\
\end{array}$ \\
\hline $\begin{array}{l}\text { Share of physical } \\
\text { capital, } \alpha_{K}\end{array}$ & $\begin{array}{c}0.221 \\
(0.032) \\
\end{array}$ & $\begin{array}{c}0.211 \\
(0.087) \\
\end{array}$ & $\begin{array}{c}0.190 \\
(0.333) \\
\end{array}$ & $\begin{array}{c}0.212 \\
(0.033) \\
\end{array}$ & $\begin{array}{c}0.219 \\
(0.028) \\
\end{array}$ & $\begin{array}{c}0.198 \\
(0.014) \\
\end{array}$ \\
\hline Returns to scale, $\gamma$ & $\begin{array}{c}1.14 \\
(0.058) \\
\end{array}$ & $\begin{array}{c}1.05 \\
(0.036) \\
\end{array}$ & $\begin{array}{c}1.03 \\
(0.333) \\
\end{array}$ & $\begin{array}{c}1.03 \\
(0.046) \\
\end{array}$ & $\begin{array}{l}1.00 \\
\text { NA }\end{array}$ & $\begin{array}{l}1.00 \\
\text { NA }\end{array}$ \\
\hline $\begin{array}{l}\text { Physical } \\
\text { depreciation rate, } \delta\end{array}$ & $\begin{array}{c}0.064 \\
(0.015)\end{array}$ & $\begin{array}{c}0.050 \\
(0.027)\end{array}$ & $\begin{array}{c}0.065 \\
(0.022)\end{array}$ & $\begin{array}{c}0.055 \\
(0.016)\end{array}$ & $\begin{array}{c}0.041 \\
(0.018)\end{array}$ & $\begin{array}{c}0.058 \\
(0.001)\end{array}$ \\
\hline Savings rate, $\sigma$ & $\begin{array}{c}0.172 \\
(0.028) \\
\end{array}$ & $\begin{array}{c}0.164 \\
(0.030) \\
\end{array}$ & $\begin{array}{c}0.186 \\
(0.027) \\
\end{array}$ & $\begin{array}{c}0.158 \\
(0.030) \\
\end{array}$ & $\begin{array}{c}0.143 \\
(0.027) \\
\end{array}$ & $\begin{array}{c}0.166 \\
(0.017) \\
\end{array}$ \\
\hline Growth rate, $g_{0}$ & $\begin{array}{c}0.0058 \\
(0.0016) \\
\end{array}$ & $\begin{array}{c}0.0086 \\
(0.0090) \\
\end{array}$ & $\begin{array}{c}0.0090 \\
(0.0089) \\
\end{array}$ & $\begin{array}{c}0.0036 \\
(0.0015) \\
\end{array}$ & $\begin{array}{c}0.0051 \\
(0.0014) \\
\end{array}$ & $\begin{array}{c}0.0050 \\
(0.0010) \\
\end{array}$ \\
\hline Growth rate, $g_{1}$ & $\begin{array}{c}0 \\
\text { NA } \\
\end{array}$ & $\begin{array}{c}0.0023 \\
(0.0077) \\
\end{array}$ & $\begin{array}{c}0.0018 \\
(0.0076) \\
\end{array}$ & $\begin{array}{c}0 \\
\text { NA } \\
\end{array}$ & $\begin{array}{c}0.0012 \\
(0.0011) \\
\end{array}$ & $\begin{array}{c}0 \\
\text { NA } \\
\end{array}$ \\
\hline TFP level, $Z_{0}$ & $\begin{array}{l}14.33 \\
(1.72) \\
\end{array}$ & $\begin{array}{l}12.70 \\
(8.43) \\
\end{array}$ & $\begin{array}{l}12.03 \\
(7.40) \\
\end{array}$ & $\begin{array}{l}13.03 \\
(1.16) \\
\end{array}$ & $\begin{array}{l}12.62 \\
(0.41) \\
\end{array}$ & $\begin{array}{l}12.68 \\
(0.14) \\
\end{array}$ \\
\hline $\begin{array}{l}\text { TFP change, } \\
Z_{1}-Z_{0} e^{g_{0}\left(t_{1}-t_{0}\right)}\end{array}$ & $\begin{array}{c}2.73 \\
(0.29)\end{array}$ & $\begin{array}{c}2.21 \\
(1.45)\end{array}$ & $\begin{array}{c}2.08 \\
(1.39)\end{array}$ & $\begin{array}{c}2.33 \\
(0.23)\end{array}$ & $\begin{array}{c}2.12 \\
(0.33)\end{array}$ & $\begin{array}{c}2.18 \\
(0.20)\end{array}$ \\
\hline \multicolumn{7}{|l|}{ Calculated parameters } \\
\hline Capital share, $\alpha$ & $\begin{array}{c}0.33 \\
(0.29,0.37) \\
\end{array}$ & $\begin{array}{c}0.30 \\
(0.12,0.47) \\
\end{array}$ & $\begin{array}{c}0.31 \\
(0.13,0.49) \\
\end{array}$ & $\begin{array}{c}0.28 \\
(0.24,0.33) \\
\end{array}$ & $\begin{array}{c}0.26 \\
(0.21,0.31) \\
\end{array}$ & $\begin{array}{c}0.28 \\
(0.25,0.31) \\
\end{array}$ \\
\hline $\begin{array}{l}\text { Share of intangible } \\
\text { capital in } M, \theta\end{array}$ & 0.33 & 0.29 & 0.39 & 0.25 & 0.16 & 0.30 \\
\hline $\begin{array}{l}\text { Test of } \\
\text { overidentifying } \\
\text { restrictions, } \mathrm{p}- \\
\text { value, } \chi^{2}(S(\cdot), 13)\end{array}$ & 0.686 & 0.599 & 0.587 & 0.678 & 0.696 & 0.616 \\
\hline
\end{tabular}


Table 2. Flow model: $Z_{0} e^{g_{0}\left(t_{1}-t_{0}\right)}=Z_{1}$

\begin{tabular}{|c|c|c|c|c|c|c|}
\hline & \multicolumn{3}{|c|}{ Labor Series 1} & \multicolumn{3}{|c|}{ Labor series 2} \\
\hline & 1972 & 1973 & 1974 & 1972 & 1973 & 1974 \\
\hline $\begin{array}{l}\text { Returns to scale } \\
\text { ( } 95 \% \text { confidence } \\
\text { interval) }\end{array}$ & $\begin{array}{c}1.34 \\
(1.20,1.47)\end{array}$ & $\begin{array}{c}1.23 \\
(1.07,1.37)\end{array}$ & $\begin{array}{c}1.15 \\
(1.02,1.29)\end{array}$ & $\begin{array}{c}1.06 \\
(0.96,1.16)\end{array}$ & $\begin{array}{c}1.09 \\
(0.98,1.20)\end{array}$ & $\begin{array}{c}1.04 \\
(0.94,1.14)\end{array}$ \\
\hline $\begin{array}{l}\text { Lagrange Multiplier } \\
\text { test (Significance): } \\
Z_{0} e^{g_{0}\left(t_{1}-t_{0}\right)}=Z_{1} \\
\end{array}$ & 0.006 & 0.004 & 0.001 & 0.004 & 0.004 & 0.001 \\
\hline $\begin{array}{l}-g_{0} / \alpha, \text { percent } \\
\left(\text { actual, } 1953-t_{1}\right)\end{array}$ & $\begin{array}{l}-1.59 \\
(-2.39)\end{array}$ & $\begin{array}{c}-2.41 \\
(-2.51)\end{array}$ & $\begin{array}{l}-2.78 \\
(-2.76)\end{array}$ & $\begin{array}{c}-2.23 \\
(-2.39)\end{array}$ & $\begin{array}{l}-2.16 \\
(-2.51)\end{array}$ & $\begin{array}{l}-2.57 \\
(-2.76)\end{array}$ \\
\hline $\begin{array}{l}-g_{1} / \alpha, \text { percent } \\
\left.\text { (actual, } t_{1}-1995\right)\end{array}$ & $\begin{array}{l}-0.97 \\
(-2.15)\end{array}$ & $\begin{array}{l}-1.72 \\
(-2.03)\end{array}$ & $\begin{array}{l}-1.77 \\
(-1.76)\end{array}$ & $\begin{array}{l}-2.05 \\
(-2.15)\end{array}$ & $\begin{array}{l}-2.12 \\
(-2.03)\end{array}$ & $\begin{array}{l}-2.05 \\
(-1.76)\end{array}$ \\
\hline \multicolumn{7}{|c|}{ Average productivity growth decomposition, shares, 1953-1995 } \\
\hline $\begin{array}{l}\text { Embodied technical } \\
\text { change }\end{array}$ & 0.33 & 0.49 & 0.56 & 0.58 & 0.55 & 0.63 \\
\hline Capital deepening & 0.30 & 0.27 & 0.27 & 0.30 & 0.28 & 0.30 \\
\hline Returns to scale & 0.37 & 0.24 & 0.17 & 0.12 & 0.17 & 0.07 \\
\hline
\end{tabular}

Table 3. Punctuated model: $g_{0}=0, g_{1}=0$

\begin{tabular}{|c|c|c|c|c|c|c|}
\hline & \multicolumn{3}{|c|}{ Labor Series 1} & \multicolumn{3}{|c|}{ Labor series 2} \\
\hline & 1972 & 1973 & 1974 & 1972 & 1973 & 1974 \\
\hline $\begin{array}{l}\text { Returns to scale }(95 \% \\
\text { confidence interval) }\end{array}$ & $\begin{array}{c}1.22 \\
(1.11,1.34) \\
\end{array}$ & $\begin{array}{c}1.29 \\
(1.17,1.42)\end{array}$ & $\begin{array}{c}1.27 \\
(1.15,1.38) \\
\end{array}$ & $\begin{array}{c}1.09 \\
(1.01,1.18) \\
\end{array}$ & $\begin{array}{c}1.11 \\
(1.03,1.20)\end{array}$ & $\begin{array}{c}1.11 \\
(1.03,1.19) \\
\end{array}$ \\
\hline $\begin{array}{l}\text { Lagrange Multiplier } \\
\text { test (Significance): } \\
g_{0}=0, g_{1}=0\end{array}$ & 0.06 & 0.02 & 0.03 & 0.13 & 0.11 & 0.13 \\
\hline$P_{0, t_{1}}^{M}=\left(\frac{Z_{0}}{Z_{1}}\right)^{1 / \alpha}$ & 0.61 & 0.66 & 0.64 & 0.57 & 0.57 & 0.60 \\
\hline $\begin{array}{l}\text { TFP change from IT } \\
\text { revolution, } Z_{1} / Z_{0}\end{array}$ & 1.19 & 1.16 & 1.18 & 1.18 & 1.17 & 1.17 \\
\hline \multicolumn{7}{|c|}{ Average productivity growth decomposition, shares, 1953-1995 } \\
\hline IT revolution & 0.37 & 0.30 & 0.32 & 0.43 & 0.42 & 0.40 \\
\hline Capital deepening & 0.35 & 0.34 & 0.34 & 0.36 & 0.35 & 0.36 \\
\hline Returns to scale & 0.28 & 0.36 & 0.34 & 0.21 & 0.23 & 0.24 \\
\hline
\end{tabular}


Table 4. Combined model

\begin{tabular}{|c|c|c|c|c|c|c|}
\hline & \multicolumn{3}{|c|}{ Labor Series 1} & \multicolumn{3}{|c|}{ Labor series 2} \\
\hline & 1972 & 1973 & 1974 & 1972 & 1973 & 1974 \\
\hline $\begin{array}{l}\text { Returns to scale } \\
\text { ( } 95 \% \text { confidence } \\
\text { interval) }\end{array}$ & $\begin{array}{c}1.14 \\
(1.03,1.25)\end{array}$ & $\begin{array}{c}1.05 \\
(0.35,1.76)\end{array}$ & $\begin{array}{c}1.03 \\
(0.38,1.69)\end{array}$ & $\begin{array}{c}1.03 \\
(0.94,1.12)\end{array}$ & $\begin{array}{l}1.00 \\
\text { NA }\end{array}$ & $\begin{array}{l}1.00 \\
\text { NA }\end{array}$ \\
\hline$g_{0}$, percent & $0.57^{*}$ & 0.86 & 0.90 & $0.36^{*}$ & $0.50^{*}$ & 0.50 \\
\hline$g_{1}$, percent & 0 & 0.23 & 0.17 & 0 & 0.12 & 0 \\
\hline $\begin{array}{l}\text { Lagrange Multiplier } \\
\text { test } \\
\text { (Significance): } \gamma=1\end{array}$ & NA & NA & NA & NA & 0.78 & 0.88 \\
\hline $\begin{array}{l}\text { Wald test } \\
\text { (Significance) } \\
g_{0}=0, g_{1}=0\end{array}$ & 0.0003 & 0.0005 & 0.0000 & 0.0171 & 0.010 & 0.0000 \\
\hline $\begin{array}{l}\text { Wald test } \\
\text { (Significance) } \\
Z_{0} e^{g_{0}\left(t_{1}-t_{0}\right)}=Z_{1} \\
\end{array}$ & 0.0000 & 0.1275 & 0.1356 & 0.0000 & 0.0000 & 0.0000 \\
\hline$P_{0, t_{1}}^{M}=\left(\frac{Z_{0}}{Z_{1}}\right)^{1 / \alpha}$ & 0.62 & 0.63 & 0.65 & 0.58 & 0.58 & 0.60 \\
\hline $\begin{array}{l}\text { TFP change from IT } \\
\text { revolution } \\
Z_{1} / Z_{0} e^{g_{0}\left(t_{1}-t_{0}\right)}\end{array}$ & 1.17 & 1.15 & 1.14 & 1.17 & 1.15 & 1.16 \\
\hline $\begin{array}{l}\text { Average rate of } \\
\text { change in the } \\
\text { relative price of } \\
\text { investment, 1953- } \\
1995, \text { percent }\end{array}$ & -1.93 & -2.89 & -2.75 & -1.88 & -2.45 & -2.09 \\
\hline \multicolumn{7}{|c|}{ Average productivity growth decomposition, shares, 1953-1995 } \\
\hline IT revolution & 0.31 & 0.26 & 0.26 & 0.41 & 0.36 & 0.38 \\
\hline $\begin{array}{l}\text { Flow embodied } \\
\text { technical change }\end{array}$ & 0.21 & 0.42 & 0.43 & 0.18 & 0.33 & 0.28 \\
\hline Capital deepening & 0.30 & 0.26 & 0.28 & 0.35 & 0.31 & 0.34 \\
\hline Returns to scale & 0.18 & 0.06 & 0.03 & 0.06 & 0 & 0 \\
\hline
\end{tabular}

